Article

\title{
Estimating Daily Maximum and Minimum Land Air Surface Temperature Using MODIS Land Surface Temperature Data and Ground Truth Data in Northern Vietnam
}

\author{
Phan Thanh Noi ${ }^{1,2, *}$, Martin Kappas ${ }^{1}$ and Jan Degener ${ }^{1}$ \\ 1 Cartography, GIS and Remote Sensing Department, Institute of Geography, University of Göttingen, \\ Goldschmidt Street 5, Göttingen 37077, Germany; mkappas@gwdg.de (M.K.); \\ jan.degener@geo.uni-goettingen.de (J.D.) \\ 2 Cartography and Geodesy Department, Land Management Faculty, Vietnam National University of \\ Agriculture, Hanoi 100000, Vietnam \\ * Correspondence: tphan1@gwdg.de; Tel.: +49-551-399-805
}

Academic Editors: Zhaoliang Li, Richard Müller and Prasad S. Thenkabail

Received: 12 September 2016; Accepted: 28 November 2016; Published: 7 December 2016

\begin{abstract}
This study aims to evaluate quantitatively the land surface temperature (LST) derived from MODIS (Moderate Resolution Imaging Spectroradiometer) MOD11A1 and MYD11A1 Collection 5 products for daily land air surface temperature $\left(T_{a}\right)$ estimation over a mountainous region in northern Vietnam. The main objective is to estimate maximum and minimum $\mathrm{T}_{\mathrm{a}}\left(\mathrm{T}_{\mathrm{a}-\mathrm{max}}\right.$ and $\left.\mathrm{T}_{\mathrm{a}-\mathrm{min}}\right)$ using both TERRA and AQUA MODIS LST products (daytime and nighttime) and auxiliary data, solving the discontinuity problem of ground measurements. There exist no studies about Vietnam that have integrated both TERRA and AQUA LST of daytime and nighttime for $\mathrm{T}_{\mathrm{a}}$ estimation (using four MODIS LST datasets). In addition, to find out which variables are the most effective to describe the differences between LST and $\mathrm{T}_{\mathrm{a}}$, we have tested several popular methods, such as: the Pearson correlation coefficient, stepwise, Bayesian information criterion (BIC), adjusted R-squared and the principal component analysis (PCA) of 14 variables (including: LST products (four variables), NDVI, elevation, latitude, longitude, day length in hours, Julian day and four variables of the view zenith angle), and then, we applied nine models for $\mathrm{T}_{\mathrm{a}-\mathrm{max}}$ estimation and nine models for $\mathrm{T}_{\mathrm{a}-\mathrm{min}}$ estimation. The results showed that the differences between MODIS LST and ground truth temperature derived from 15 climate stations are time and regional topography dependent. The best results for $\mathrm{T}_{\mathrm{a}-\mathrm{max}}$ and $\mathrm{T}_{\mathrm{a}-\mathrm{min}}$ estimation were achieved when we combined both LST daytime and nighttime of TERRA and AQUA and data from the topography analysis.
\end{abstract}

Keywords: land surface temperature (LST); MODIS LST products; northern Vietnam

\section{Introduction}

Land air surface temperature ( $T_{a}$, also called "air temperature" or "near surface temperature") data are usually collected as point data from weather station locations, typically at $2 \mathrm{~m}$ above the land surface. It is an important parameter in a wide range of fields, such as agriculture, e.g., crop evapotranspiration [1], crop yield prediction [2,3], hydrology [4,5], ecology, environment and climate change [6,7]. Generally, $T_{a}$ values obtained from weather stations have a very high accuracy and temporal resolution [8], but do not capture information for a whole region and may therefore be unsuitable for spatial modelling applications [9-11].

In order to obtain $T_{a}$ information for a region, researchers have proposed various methods of interpolation based on known weather station sites [12-14]. These interpolation methods' accuracy is 
highly dependent on the weather station network density, as well as the scale of spatial and temporal variability $[15,16]$. Furthermore, station geometry and topography (elevation) change also affects the accuracy of interpolation, especially in regions with a wide range of elevation $[17,18]$. However, the spatial distribution of weather stations is often limited in developing countries. Our study area of Vietnam has 170 surface meteorological observing stations, including 97 synoptic and 26 international exchange stations [19], which is obviously inadequate for a country with an area of $331,688 \mathrm{~km}^{2}$ in which about $40 \%$ is mountainous, $40 \%$ hill and the remaining $20 \%$ lowland. Therefore, interpolation techniques may not be suitable for Vietnam.

Fortunately, remote sensing data provide a promising solution to overcome the limitation of interpolation techniques in mountainous areas and a sparsity of weather station areas. The successful launch of the Advanced Very High-Resolution Radiometer (AVHRR) in 1981 and the Moderate Resolution Imaging Spectroradiometer (MODIS) on board TERRA (December 1999) and AQUA (May 2002) has driven researchers to study new satellite-based methods, as a hot topic in recent years [16,20-25].

In recent years, there have been more and more studies employing land surface temperature (LST) obtained from remotely-sensed images for $\mathrm{T}_{\mathrm{a}}$ estimation because of high spatial and temporal resolution, free availability and easy access. Particularly, MODIS on board TERRA and AQUA can provide daily LST data with high temporal (four times per day, TERRA LST daytime, TERRA LST nighttime, AQUA LST daytime, AQUA LST nighttime, which overpass local time at around 10:30 a.m., 10:30 p.m., 1:30 a.m. and 1:30 p.m., respectively) and very high spatial resolution (1 km) are widely applied. The difference between LST and $\mathrm{T}_{\mathrm{a}}$ is strongly influenced by the surface characteristics and atmospheric conditions [26,27]. In some regions, the difference between LST and $\mathrm{T}_{\mathrm{a}}$ is high $[17,28]$. However, researchers from all over the world state that there is a strong linear correlation between MODIS LST and $\mathrm{T}_{\mathrm{a}}$ over many regions, e.g., in Africa [15], in Portugal [29], over the U.S. [30,31] and in Southeast Asia [32,33]. The detailed information of this difference, as well as the possible causes of this difference are still limited and need to be studied.

Some researchers $[29,31,34]$ reviewed the types of commonly-used methods for $\mathrm{T}_{\mathrm{a}}$ estimation based on LST. There are three main distinct types of methods:

The first type is the temperature-vegetation index method (TVX), which is based on the assumption that in an absolutely thick canopy, the temperature at the top of the canopy is the same as within the canopy [35]; and there is a strong negative correlation between LST and the vegetation index, such as NDVI [9,10,36-39]. However, in some cases, this method is not satisfying due to the assumption that it often does not fit to the reality or the effect of seasonality, land cover type or soil moisture $[15,40]$.

The second type includes the surface energy-balance-based methods. The sum of in-coming net radiation and anthropogenic heat fluxes is considered equal to the sum of the surface's sensible and latent heat fluxes [41]. The major drawback of these methods is that they require large amounts of information often not provided by remote sensing [24,25].

The last type is using statistical methods that are based on regression techniques. These methods include various levels of complexity, from basic approaches that only use LST for $\mathrm{T}_{\mathrm{a}}$ estimation [16,25] to advanced approaches that use more than one independent variable, such as elevation, NDVI, land cover, distance to water body, solar zenith angle, day length in hours, latitude and altitude [15,29,32,42-44]. One of the biggest advantages of this method is that the systematic regional errors in satellite data can be reduced [45].

The most recently popular studies of $\mathrm{T}_{\mathrm{a}}$ estimation using statistic approaches are shown in Table 1.

However, most of these studies have only used LST daytime and LST nighttime solely for $\mathrm{T}_{\mathrm{a}}$ maximum $\left(\mathrm{T}_{\mathrm{a}-\max }\right)$ and $\mathrm{T}_{\mathrm{a}}$ minimum $\left(\mathrm{T}_{\mathrm{a}-\mathrm{min}}\right)$ estimation, respectively. In a recent study [31], both LST nighttime and daytime were used for $\mathrm{T}_{\mathrm{a}-\max }$ and for $\mathrm{T}_{\mathrm{a}-\mathrm{min}}$ estimation. However, this study was only applied for the growing season (May-September) from 2008-2012, and the elevation of the study site 
(the Corn Belt region of the Midwestern U.S.) ranging from 87-666 m and mostly covered by crops has a small vegetation index range.

Table 1. List of daily $\mathrm{T}_{\mathrm{a}}$ temperature estimation studies using MODIS LST products in recent years. TVX, temperature-vegetation index.

\begin{tabular}{|c|c|c|c|}
\hline Authors & Methods & Accuracy of $\mathrm{T}_{\mathrm{a}-\mathrm{max}}, \mathrm{T}_{\mathrm{a}-\mathrm{min}}$ Estimation $\left({ }^{\circ} \mathrm{C}\right)$ & Study Region \\
\hline Vancutsem et al. [15] & Statistical approach & RMSE $=2.1-2.76$ & Africa \\
\hline Shen and Leptoukh [46] & Statistical approach & $\begin{array}{l}\text { Daily } \mathrm{T}_{\mathrm{a}-\mathrm{max}} \text { : MAE: } 2.4-3.2 \\
\text { Daily } \mathrm{T}_{\mathrm{a}-\mathrm{min}} \text { : MAE: } 3.0\end{array}$ & Central and eastern Eurasia \\
\hline Zhu et al. [38] & TVX & $\begin{array}{l}\mathrm{T}_{\mathrm{a}-\max }: \mathrm{RMSE}=3.79, \mathrm{MAE}=3.03, \mathrm{r}=0.83 \\
\mathrm{~T}_{\mathrm{a}-\min }: \mathrm{RMSE}=2.97, \mathrm{MAE}=2.37, \mathrm{r}=0.94\end{array}$ & Xiangride River Basin of China \\
\hline Emamifar et al. [47] & M5 model tree & Daily $\mathrm{T}_{\mathrm{a}-\mathrm{mean}}: \mathrm{RMSE}=2.3, \mathrm{r}^{2}=0.96$ & Southwest of Iran \\
\hline Xu et al. [48] & Statistical approach & $\mathrm{T}_{\mathrm{a}-\max }:$ MAE: $2.02 ; \mathrm{r}=0.74$ & western Canada \\
\hline Zeng et al. [31] & Statistical approach & $\begin{array}{l}\mathrm{T}_{\mathrm{a}-\max }: \mathrm{RMSE}=2.15-4.27, \mathrm{MAE}=1.71-3.35 \\
\mathrm{~T}_{\mathrm{a}-\mathrm{min}}: \mathrm{RMSE}=1.75-5.13, \mathrm{MAE}=1.30-4.06\end{array}$ & The Corn Belt over U.S. \\
\hline Huang et al. [33] & Statistical approach & Daily $\mathrm{T}_{\mathrm{a}-\mathrm{mean}}: \mathrm{RMSE}=2.41, \mathrm{MAE}=1.84$ & Central China \\
\hline
\end{tabular}

RMSE: root mean square error; MAE: mean absolute error; $r$ : correlation coefficient; $\mathrm{r}^{2}$ : determination coefficients.

There are several researchers who have studied the effect of the time of observation on the relationship between LST and $T_{a}$, but the conclusions are quite different in various time and geographical regions of the study areas. For instance, [25] found that the overpass time of TERRA and AQUA has little impact on the accuracy of $\mathrm{T}_{\mathrm{a}}$ estimation in Mississippi State. Zhang et al. [39] concluded that for daily $\mathrm{T}_{\mathrm{a}}$ estimation, TERRA LST and AQUA LST give the same results. Benali et al. [29] showed that the use of both AQUA LST daytime and LST nighttime gives better accuracy of $\mathrm{T}_{\mathrm{a}-\max }$ and $\mathrm{T}_{\mathrm{a}-\text {-min }}$ estimation, respectively, than TERRAs in Portugal. In contrast, [38] stated that TERRA LST daytime and TERRA nighttime were better than AQUA LST daytime and nighttime for $\mathrm{T}_{\mathrm{a}}$ estimation. These differences could be understood as not only the time of observation, but also geographical location affecting the relationship between LST products and $\mathrm{T}_{\mathrm{a}}$ and, therefore, affecting the accuracy estimation of $\mathrm{T}_{\mathrm{a}}$ based on LST products. Because of all of these different conclusions about the relationship between $T_{a}$ and LST of TERRA and AQUA, in this study, we analyzed the relationship between $\mathrm{T}_{\mathrm{a}}$ with both TERRA LST and AQUA LST products.

In addition, as far as we know, there are no studies over Vietnam that have integrated both TERRA and AQUA LST of daytime and nighttime for $\mathrm{T}_{\mathrm{a}}$ estimation (using all four MODIS LST datasets).

The main objective of this research was to estimate daily $\mathrm{T}_{\mathrm{a}}$ (maximum and minimum) using both TERRA and AQUA MODIS LST products (daytime and nighttime) and auxiliary data, solving the discontinuity problem of ground measurements. In addition, to find out which variables, among 14 predefined variables, are the most effective to describe the relationship between LST and $T_{a}$, we have tested several methods, such as: the Pearson correlation coefficient, forward selection, backward elimination, stepwise, Bayesian information criterion (BIC), adjusted R-squared and the principal component analysis (PCA) of 14 variables (including: LST products (four variables), NDVI, elevation, latitude, longitude, day length in hours, Julian day and four variables of the view zenith angle). Finally, we applied nine models for $\mathrm{T}_{\mathrm{a}-\mathrm{max}}$ and nine models for $\mathrm{T}_{\mathrm{a}-\mathrm{min}}$ estimation.

\section{Materials and Methods}

\subsection{Study Area}

The study area is located in northern Vietnam and covers more than $37,000 \mathrm{~km}^{2}$, comprising the provinces of Hoa Binh, Ha Noi, Vinh Phuc, Thai Nguyen, Yen Bai, Phu Tho and Son La (see Figure 1). The study area extends from $20^{\circ} 18^{\prime} \mathrm{N}-22^{\circ} 40^{\prime} \mathrm{N}$ and from $103^{\circ} 12^{\prime} \mathrm{E}-106^{\circ} 18^{\prime} \mathrm{E}$. The elevation ranges from sea level to over $3000 \mathrm{~m}$.

The northern Vietnam study site was chosen for the following reasons: 
(1) Good distribution of meteorological station network in comparison to southern Vietnam.

(2) Wide range of elevation (from approximately sea level to more than $3000 \mathrm{~m}$ ).

(3) The spatial heterogeneity of land cover.

(4) There is no study about $T_{a}$ estimation using all 4 MODIS LST datasets in northern Vietnam.

In this area, the topography is quite complex, increasing from southeast to northwest, and mostly divided into two regions: lowland and highland. The low part includes: Hoabinh, Hanoi, Phutho, Vinhphuc and Thainguyen provinces. The high part includes 2 large provinces: a part of Yenbai and Sonla.

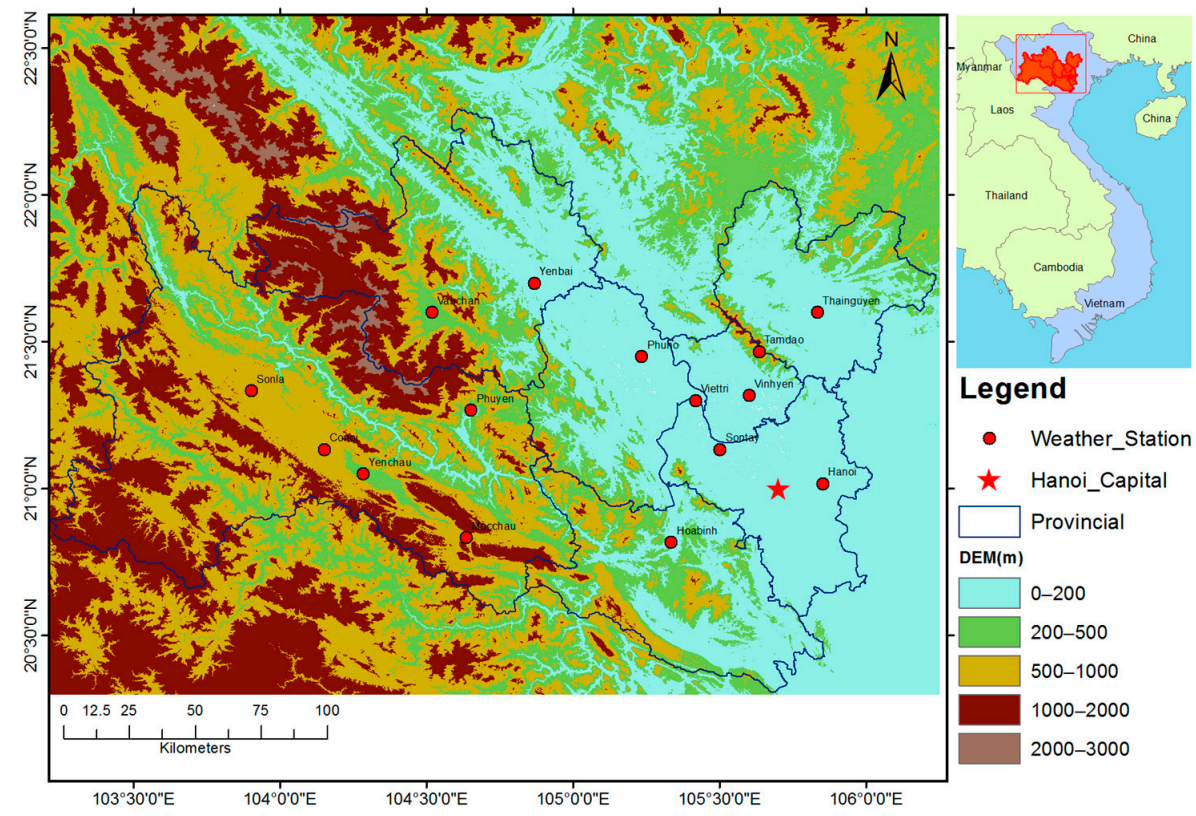

Figure 1. Location of the 15 meteorological stations in northern Vietnam and the range of elevations in the study area.

The climate and weather in this area also vary depending on the elevation and type of landscape. The humidity is high, with the average ranging around $84 \%$ a year.

In late October and early November 2008, there was torrential rain in northern and central Vietnam that triggered severe floods in this region [49].

The location and elevation of meteorological stations are shown in Table 2.

Table 2. Geographical description of weather stations used in this study.

\begin{tabular}{cccc}
\hline Weather Station & Latitude $\left.\mathbf{(}^{\circ}\right)$ & Longitude $\left(^{\circ}\right)$ & Elevation $(\mathbf{m})$ \\
\hline Conoi & 21.13 & 104.15 & 671 \\
Hanoi & 21.02 & 105.80 & 6 \\
Hoabinh & 20.82 & 105.33 & 23 \\
Mocchau & 20.83 & 104.68 & 972 \\
Phuho & 21.45 & 105.23 & 54 \\
Phuyen & 21.27 & 104.63 & 169 \\
Sonla & 21.33 & 103.90 & 675 \\
Sontay & 21.13 & 105.50 & 16 \\
Tamdao & 21.47 & 105.65 & 934 \\
Thainguyen & 21.60 & 105.83 & 35 \\
Vanchan & 21.58 & 104.52 & 275 \\
Viettri & 21.30 & 105.42 & 30 \\
Vinhyen & 21.32 & 105.60 & 10 \\
Yenbai & 21.70 & 104.87 & 56 \\
Yenchau & 21.05 & 104.30 & 314 \\
\hline & & &
\end{tabular}




\subsection{Data}

\subsubsection{Remote Sensing Data}

\section{MODIS LST Data}

Two MODIS LST products (h27v06, Collection 5, from 2003-2013, over northern Vietnam) were used in this study: MOD11A1 daily land surface temperature and emissivity from the TERRA satellites and MYD11A1 daily land surface temperature and emissivity from the AQUA satellites. There exist 4 LST data records per day, two from the TERRA satellites and two others from the AQUA satellites, which pass over the study site (local solar time) mostly around 10:30 a.m., p.m. and 1:45 a.m. and p.m., respectively. These times are relatively close to the times of maximum and minimum $T_{a}$ daily data. In total, there were more than 8000 images (in HDF format, from 1 January 2003-31 December 2013) downloaded from the U.S. Geological Survey [50]. The MODIS LST is generated using a split-window algorithm [51] with two thermal infrared bands, $31(10.78-11.28 \mu \mathrm{m})$ and $32(11.77-12.27 \mu \mathrm{m})$. These two products (MOD11A1 and MYD11A1) have been validated, and the accuracy was reported better than $1 \mathrm{~K}$ under clear sky conditions [52].

Elevation

In this study area, the elevation is quite complex; it ranges from sea level to above $3000 \mathrm{~m}$ (see Figure 1). Generally, higher elevations are associated with lower temperatures. Elevation data were obtained from ASTER Global DEM. This data are available from the U.S. Geological Survey (USGS) with a spatial resolution of $30 \mathrm{~m}$. These elevation data were resized to $1-\mathrm{km}$ resolution using the nearest neighbor resampling type in order to be associated with other data resolutions, such as MODIS LST or NDVI data.

\section{Vegetation Based on NDVI}

Several studies have shown that the vegetation cover on the surface can affect LST values [53]. Vegetation cover (NDVI) data are provided every 16 days at 1-kilometer spatial resolution from the MODIS satellite, including MOD13A2 (TERRA 16-days period starting Day 001) and MYD13A2 (AQUA 16-day period starting Day 009). There are some studies that use both MOD13A2 and MYD13A2 in order to composite 8-day period data by averaging these two products [18]. Miura and Yoshioka [54] stated that MOD13A2 and MYD13A2 could be interchangeable. We assumed that NDVI did not change within 16 days. Therefore, in this study, to correct the influence of vegetation, we used NDVI 16 days data at 1-km resolution obtained from the MOD13A2 product.

\subsubsection{Meteorological Data}

Daily maximum and minimum air temperature data have been collected from 15 meteorological stations in northern Vietnam (see Figure 1), from 2003-2013. The data were obtained from the Vietnam Institute of Meteorology, Hydrology and ENvironment (IMHEN).

\subsubsection{Auxiliary Data}

Day length (Dlth) is the total time that any portion of the Sun is above the horizon. Typically (for low and mid-latitude locations), this will be the elapsed time beginning at sunrise and ending at sunset [55]. In this study, the day length (in hours) was downloaded from the Astronomical Applications Department of the U.S. Naval Observatory website [55].

The Julian day (Jd) was extracted from NASA server [56]. Both Julian day and day length are proxies for the fraction of solar energy absorption during the day and emitted energy during the night, influencing the diurnal amplitude of $T_{a}$ throughout the year. Jang et al. [57] showed that the Julian day was a more significant parameter than altitude or the solar zenith angle in the inter-seasonal 
estimation of $\mathrm{T}_{\mathrm{a}}$. In order to understand the effect of viewing angle in the temporal variations in LST, especially in rugged regions, the view zenith angle (VZA) of daytime and nighttime should be taken into consideration [58]. In this study, there are four types of VZA of TERRA daytime, TERRA nighttime, AQUA daytime, AQUA nighttime $\left(\mathrm{VZA}_{\mathrm{td}}, \mathrm{VZA}_{\mathrm{tn}}, \mathrm{VZA}_{\mathrm{ad}}, \mathrm{VZA}_{\mathrm{an}}\right.$, respectively). These data were collected from MOD11A1 and MYD11A1 products. We also took the effects of the latitude, longitude and elevation of each station, collected from IMHEN, into consideration to estimate $\mathrm{T}_{\mathrm{a}}$ accuracy. All key terms and their explanations are summarized in Table 3.

Table 3. Description of the key terminology used in this study.

\begin{tabular}{|c|c|}
\hline Used Terms & Description \\
\hline $\mathrm{T}_{\mathrm{a}}\left({ }^{\circ} \mathrm{C}\right)$ & Land air surface temperature \\
\hline $\mathrm{T}_{\mathrm{a}-\max }\left({ }^{\circ} \mathrm{C}\right)$ & Daily Maximum $\mathrm{T}_{\mathrm{a}}$ \\
\hline $\mathrm{T}_{\mathrm{a}-\min }\left({ }^{\circ} \mathrm{C}\right)$ & Daily Minimum $\mathrm{T}_{\mathrm{a}}$ \\
\hline LST $\left({ }^{\circ} \mathrm{C}\right)$ & Land surface temperature \\
\hline $\mathrm{LST}_{\mathrm{td}}\left({ }^{\circ} \mathrm{C}\right)$ & TERRA LST daytime \\
\hline $\mathrm{LST}_{\operatorname{tn}}\left({ }^{\circ} \mathrm{C}\right)$ & TERRA LST nighttime \\
\hline $\mathrm{LST}_{\mathrm{ad}}\left({ }^{\circ} \mathrm{C}\right)$ & AQUA LST daytime \\
\hline $\mathrm{LST}_{\text {an }}\left({ }^{\circ} \mathrm{C}\right)$ & AQUA LST nighttime \\
\hline $\mathrm{T}_{\text {a-min-es }}\left({ }^{\circ} \mathrm{C}\right)$ & Daily minimum $\mathrm{T}_{\mathrm{a}}$ estimation \\
\hline $\mathrm{T}_{\text {a-max-es }}\left({ }^{\circ} \mathrm{C}\right)$ & Daily maximum $\mathrm{T}_{\mathrm{a}}$ estimation \\
\hline Ele $(\mathrm{m})$ & Elevation of weather stations \\
\hline NDVI & Normalized Difference Vegetation Index \\
\hline Long $\left(^{\circ}\right)$ & Longitude \\
\hline Lat $\left(^{\circ}\right)$ & Latitude \\
\hline Dlth (hours) & Day length in hours \\
\hline Jd & Julian day \\
\hline $\mathrm{VZA}_{\mathrm{td}}$ & View zenith angle of TERRA daytime \\
\hline $\mathrm{VZA}_{\mathrm{tn}}$ & View zenith angle of TERRA nighttime \\
\hline $\mathrm{VZA}_{\mathrm{ad}}$ & View zenith angle of AQUA daytime \\
\hline $\mathrm{VZA}_{\text {an }}$ & View zenith angle of AQUA nighttime \\
\hline
\end{tabular}

\subsection{Preprocessing Data}

There were 8036 files of MODIS HDF format (MOD11A1 and MYD11A1, Version 5) from 1 January 2003-31 December 2013 that were downloaded for this study. Because all MODIS data were downloaded from USGS in HDF format (Hierarchical Data Format), with each file containing 12 data layers [58], we used the MODIS Reprojection Tool to extract the corresponding bands (LST_Day_1km, LST_Night_1 km and view zenith angle) from MOD11A1 and MYD11A1. Next, we used the layer stacking tool in Envi5.0 to stack images for time series analysis purposes, before clipping the images to fit to our study area using ArcGIS 10.1.

\subsection{LST Data Retrieval at Weather Stations}

LST data under clear sky conditions at weather stations were retrieved by the following steps:

(1) MODIS LST day and night was extracted from MOD11A1 and MYD11A1 data for the pixel in which the meteorological stations are located. It should be noted that in the MODIS LST (v005) product, LST values derived from a single clear-sky MODIS observation are selected from MOD11_L2 files if the viewing zenith angles are small or larger zenith angles have LST errors smaller than $2 \mathrm{~K}$ [58]. This means that MOD11A1 and MYD11A1 LST were not produced for pixels that are classed as cloudy or cloud contamination remaining.

(2) However, [58] also noted that pixels that are lightly or modestly cloud contaminated are not removed by using cloud-removing masks if the contamination is smaller than the normal temporal variations in clear-sky LST. Typically, these are thin and subpixel clouds that are difficult to detect by the algorithm. In this case, we applied two steps to remove those types of errors. First, we simply filter and remove all unrealistic LST data that had values greater than $100{ }^{\circ} \mathrm{C}$ and below $-50{ }^{\circ} \mathrm{C}$. Second, we calculated the difference between $\mathrm{T}_{\mathrm{a}-\mathrm{max}}$ versus LST daytime and $\mathrm{T}_{\mathrm{a}-\mathrm{min}}$ versus LST nighttime. Then, 
we applied a statistic outlier removal based on these differences' histograms to detect and remove data with unusually large differences.

(3) All valid LST day and nighttime data of TERRA and AQUA were statistical compared with $\mathrm{T}_{\mathrm{a}-\mathrm{max}}$ and $\mathrm{T}_{\mathrm{a}-\mathrm{min}}$, respectively.

\subsection{Estimation of Land Air Surface Temperature Using MODIS LST and Auxiliary Data}

The method for this study was based on a multivariate linear regression analysis. This method was chosen because it could be applied for sparse meteorological station networks like northern Vietnam. Although some interpolation methods may give a higher accuracy result, they are not possible for regions with poorly-distributed station networks [59]; or physical models [41] that require an unreliable amount of input data.

\subsubsection{Variable Selection}

Zaksek and Schroedter-Homscheidt [34] stated that $T_{a}$ is driven more by LST than by direct solar radiation, meaning that LST is the most important variable for $\mathrm{T}_{\mathrm{a}}$ estimation; in reference to previous studies $[15,29,31,42,57]$, also in consideration of all of the available data that potentially have an effect on the accuracy of $T_{a}$ estimation of the study area. We have collected 14 variables, including: LST products (4 variables), NDVI, elevation (DEM), latitude, longitude, day length in hours and Julian day, and 4 variables of the view zenith angle as the potential variables (candidate variables) for $\mathrm{T}_{\mathrm{a}}$ estimation.

Besides the 4 LST variables, we chose NDVI because it influences the land surface vegetation properties. Elevation, latitude and longitude were chosen for capturing the variability of climatic conditions between different regions. Day length in hours was chosen because we considered that it would affect the received solar radiation. Following [45,57], we chose Julian day because it reflects seasonal variation in air temperature. The view zenith angle was considered as a factor affecting the accuracy of LST data.

Since we have 14 potential variables (predictors), there are $2^{14}(=16,384)$ possible models that could be applied for $\mathrm{T}_{\mathrm{a}-\mathrm{max}}$ and $\mathrm{T}_{\mathrm{a}-\mathrm{min}}$ estimation. Clearly, we cannot apply all of these possible models and test them one by one. Consequently, to save the time of data processing and to find the smallest model that best fits the data, we selected the best subset of variables among the 14 available variables.

In this study, we used several popular methods for variable selection, such as: (1) the Pearson correlation coefficient; (2) stepwise; (3) Bayesian information criterion (BIC); (4) adjusted R-squared; and (5) principal component analysis (PCA).

\section{Pearson Correlation Coefficient}

To select the variables for the multivariate linear regression models, we calculated the Pearson's correlation coefficient ( $\mathrm{r}$ ) of all related variables. According to [11], $\mathrm{r}$ close to \pm 1 indicates a strong correlation; $\mathrm{r}=0$ means that there is no correlation; $0.25 \leq \mathrm{r} \leq 0.75$, means there is a moderate degree of correlation and $0 \leq \mathrm{r}<0.25$, a weak correlation. Based on this, we took only variables with $\mathrm{r}$ greater than 0.25 for $\mathrm{T}_{\mathrm{a}}$ estimation.

The results in Table 4 show that we should use 7 variables for $\mathrm{T}_{\mathrm{a}-\mathrm{min}}$ estimated models (4 LST, Ele, Long and Dlth); and 7 other variables for $\mathrm{T}_{\mathrm{a}-\max }$ estimated models (4 LST, Ele, Dlth and Jd).

Variable Selection Based on Adjusted R-Squared $\left(\overline{\mathrm{R}}^{2}\right)$ and BIC

$$
\overline{\mathrm{R}}^{2}=1-\left(1-\mathrm{r}^{2}\right) \frac{\mathrm{N}-1}{\mathrm{~N}-\mathrm{k}-1},
$$

The best model will be the one with the largest value of $\overline{\mathrm{R}}^{2}$ :

$$
\mathrm{BIC}=\mathrm{N} \log \left(\frac{\mathrm{SSE}}{\mathrm{N}}\right)+(\mathrm{k}+2) \log (\mathrm{N}),
$$


Minimizing the BIC is intended to give the best model.

$\mathrm{N}$ is the number of observations; $\mathrm{k}$ is the number of predictors (variables); $\mathrm{r}^{2}$ is the coefficient of determination; and SSE is the sum of squared error.

In Figure 2, colored parts (green for $\overline{\mathrm{R}}^{2}$ and orange for BIC) indicate that a variable was included in the model and white color that a variable was not included in the model. All of these models include the intercept.
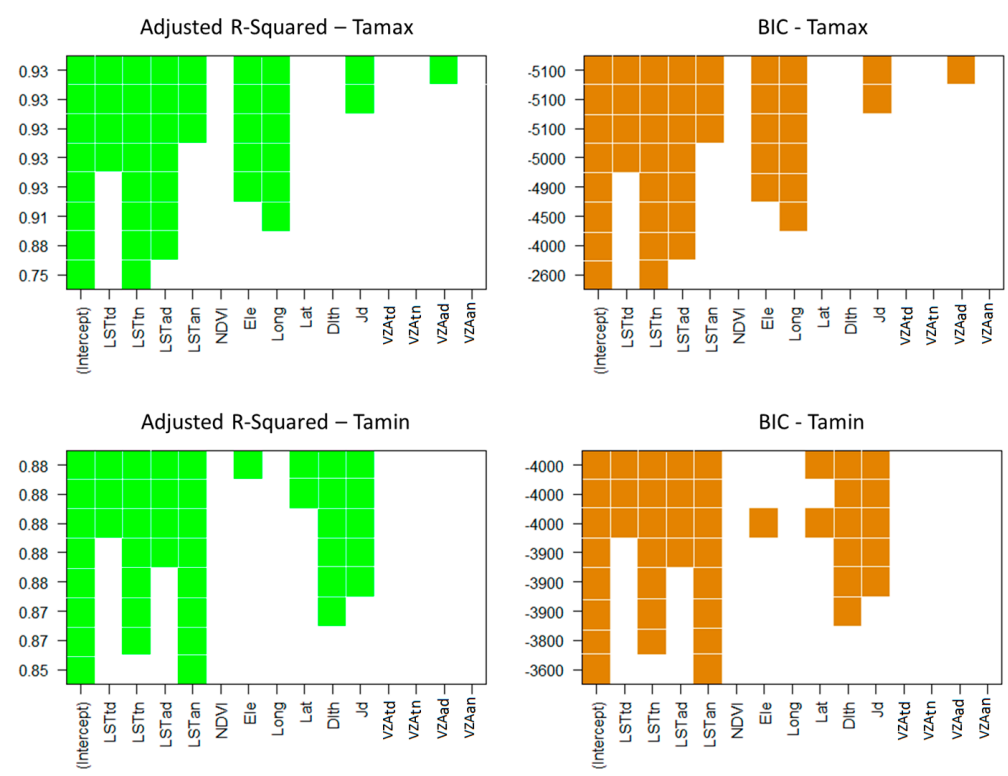

Figure 2. Ranking of models based on $\overline{\mathrm{R}}^{2}$ and BIC criteria for $\mathrm{T}_{\mathrm{a}-\mathrm{max}}$ (upper row panel) and $\mathrm{T}_{\mathrm{a}-\mathrm{min}}$ (lower row panel) estimation.

Table 4. Pearson correlation coefficients of all variables considered in models for daily $\mathrm{T}_{\mathrm{a}-\mathrm{max}}$ and $\mathrm{T}_{\mathrm{a}-\mathrm{min}}$ estimation.

\begin{tabular}{|c|c|c|c|c|c|c|c|c|c|c|c|c|c|c|}
\hline & $\mathrm{LST}_{\mathrm{td}}$ & $\mathrm{LST}_{\mathrm{tn}}$ & $\mathrm{LST}_{\mathrm{ad}}$ & $\mathrm{LST}_{\text {an }}$ & NDVI & Ele & Long & Lat & Dlth & Jd & $\mathrm{VZA}_{\mathrm{td}}$ & $\mathrm{VZA}_{\text {tn }}$ & $\mathrm{VZA}_{\mathrm{ad}}$ & $\mathbf{V Z A}_{\text {an }}$ \\
\hline $\mathrm{T}_{\mathrm{a}-\min }$ & 0.68 & 0.92 & 0.61 & 0.92 & 0.03 & -0.29 & 0.27 & -0.01 & 0.75 & -0.17 & 0.00 & 0.01 & -0.03 & -0.01 \\
\hline $\mathrm{T}_{\mathrm{a}-\mathrm{max}}$ & 0.85 & 0.86 & 0.86 & 0.82 & -0.18 & -0.28 & -0.10 & -0.08 & 0.68 & -0.36 & -0.01 & 0.03 & -0.03 & -0.03 \\
\hline
\end{tabular}

Looking at the $\mathrm{y}$-axis of Figure 2, it can be clearly seen that, in both cases of $\mathrm{T}_{\mathrm{a}-\mathrm{max}}$ and $\mathrm{T}_{\mathrm{a}-\mathrm{min}}$, the top three models have the same results of $\overline{\mathrm{R}}^{2}$ and BIC.

In this case, we chose all top 3 models for $T_{a}$ estimation. These model forms are as follows:

$$
\begin{aligned}
& \mathrm{T}_{\mathrm{a}-\mathrm{max}}=\mathrm{a} \times \mathrm{LST}_{\mathrm{td}}+\mathrm{b} \times \mathrm{LST}_{\mathrm{tn}}+\mathrm{c} \times \mathrm{LST}_{\mathrm{ad}}+\mathrm{d} \times \mathrm{LST}_{\mathrm{an}}+\mathrm{e} \times \text { Ele }+\mathrm{f} \times \text { Long }+\mathrm{g} \times \mathrm{Jd}+\mathrm{h} \times \mathrm{VZAad}+\mathrm{i}, \\
& \mathrm{T}_{\mathrm{a}-\max }=\mathrm{a} \times \mathrm{LST}_{\mathrm{td}}+\mathrm{b} \times \mathrm{LST}_{\mathrm{tn}}+\mathrm{c} \times \mathrm{LST}_{\mathrm{ad}}+\mathrm{d} \times \mathrm{LST}_{\mathrm{an}}+\mathrm{e} \times \mathrm{Ele}+\mathrm{f} \times \text { Long }+\mathrm{g} \times \mathrm{Jd}+\mathrm{h}, \\
& \mathrm{T}_{\mathrm{a}-\max }=\mathrm{a} \times \mathrm{LST}_{\mathrm{td}}+\mathrm{b} \times \mathrm{LST}_{\mathrm{tn}}+\mathrm{c} \times \mathrm{LST}_{\mathrm{ad}}+\mathrm{d} \times \mathrm{LST}_{\mathrm{an}}+\mathrm{e} \times \text { Ele }+\mathrm{f} \times \text { Long }+\mathrm{g}, \\
& \mathrm{T}_{\mathrm{a}-\min }=\mathrm{a} \times \mathrm{LST}_{\mathrm{td}}+\mathrm{b} \times \mathrm{LST}_{\mathrm{tn}}+\mathrm{c} \times \mathrm{LST}_{\mathrm{ad}}+\mathrm{d} \times \mathrm{LST}_{\mathrm{an}}+\mathrm{e} \times \text { Dlth }+\mathrm{f} \times \text { Lat }+\mathrm{g} \times \mathrm{Jd}+\mathrm{h} \times \text { Ele }+\mathrm{i} \text {, } \\
& \mathrm{T}_{\mathrm{a}-\mathrm{min}}=\mathrm{a} \times \mathrm{LST}_{\mathrm{td}}+\mathrm{b} \times \mathrm{LST}_{\mathrm{tn}}+\mathrm{c} \times \mathrm{LST}_{\mathrm{ad}}+\mathrm{d} \times \mathrm{LST}_{\mathrm{an}}+\mathrm{e} \times \text { Dlth }+\mathrm{f} \times \text { Lat }+\mathrm{g} \times \mathrm{Jd}+\mathrm{h}, \\
& \mathrm{T}_{\mathrm{a}-\min }=\mathrm{a} \times \mathrm{LST}_{\mathrm{td}}+\mathrm{b} \times \mathrm{LST}_{\mathrm{tn}}+\mathrm{c} \times \mathrm{LST}_{\mathrm{ad}}+\mathrm{d} \times \mathrm{LST}_{\mathrm{an}}+\mathrm{e} \times \text { Dlth }+\mathrm{f} \times \mathrm{Jd}+\mathrm{g} .
\end{aligned}
$$

Variable Selection Using Forward, Backward and Stepwise

Another popular method that is used for variable selection is the stepwise method. In this method, there are three types of operative steps: forward, backward and stepwise. 
Forward selection starts with no variable in the model (intercept only model). In the next steps, the most significant variables are added to the model one by one. The process stops when all of the variables not in the model have a $p$-value greater than 0.15 .

Backward elimination starts with the model including all variables. In the next step, the least significant variable will be removed. The procedure continues until all of the variables in the model have $p$-values less than or equal to 0.15 .

The stepwise method adds or removes a variable in each step, depending on its $p$-value. This process continues until all variables within the model have a $p$-value $\leq 0.15$, and all of the variables that were not in the model have a $p$-value $>0.15$.

Based on the results of forward, backward and stepwise selection, the $\mathrm{T}_{\mathrm{a}-\mathrm{max}}$ estimated model should include 12 variables (using all variables except $\mathrm{VZA}_{\mathrm{tn}}$ and $\mathrm{VZA}_{\mathrm{an}}$ ); the $\mathrm{T}_{\mathrm{a} \text {-min }}$ estimated model should include 10 variables (except long, $V_{2 A}, V_{a n} A_{t d}, V A_{t n}$ ).

The $\mathrm{T}_{\mathrm{a}-\mathrm{max}}$ and $\mathrm{T}_{\mathrm{a}-\mathrm{min}}$ estimated models were as follows:

$$
\begin{aligned}
& \mathrm{T}_{\mathrm{a}-\text { max }}=\mathrm{a} \times \mathrm{LST}_{\mathrm{td}}+\mathrm{b} \times \mathrm{LST}_{\mathrm{tn}}+\mathrm{c} \times \mathrm{LST}_{\mathrm{ad}}+\mathrm{d} \times \mathrm{LST}_{\mathrm{an}}+\mathrm{e} \times \mathrm{NDVI}+\mathrm{f} \times \text { Ele }+\mathrm{g} \times \text { Long } \\
& +\mathrm{h} \times \text { Lat }+\mathrm{i} \times \text { Dlth }+\mathrm{j} \times \mathrm{Jd}+\mathrm{k} \times \mathrm{VZA}_{\mathrm{td}}+1 \times \mathrm{VZA}_{\mathrm{ad}}+\mathrm{m}, \\
& \mathrm{T}_{\mathrm{a}-\min }=\mathrm{a} \times \mathrm{LST}_{\mathrm{td}}+\mathrm{b} \times \mathrm{LST}_{\mathrm{tn}}+\mathrm{c} \times \mathrm{LST}_{\mathrm{ad}}+\mathrm{d} \times \mathrm{LST}_{\mathrm{an}}+\mathrm{e} \times \mathrm{NDVI}+\mathrm{f} \times \mathrm{Ele}+\mathrm{g} \times \mathrm{Lat} \\
& +\mathrm{h} \times \text { Dlth }+\mathrm{i} \times \mathrm{Jd}+\mathrm{j} \times \mathrm{VZA}_{\mathrm{ad}}+\mathrm{k} \text {, }
\end{aligned}
$$

Variable Selection-Based Principal Component Analysis (PCA)

The result of the PCA showed that both $\mathrm{T}_{\mathrm{a}-\mathrm{max}}$ and $\mathrm{T}_{\mathrm{a}-\mathrm{min}}$ estimation models should include 4 LST, elevation, day length in hours and Julian day.

$\mathrm{T}_{\mathrm{a}-\max }=\mathrm{T}_{\mathrm{a}-\text { min }}=\mathrm{a} \times \mathrm{LST}_{\mathrm{td}}+\mathrm{b} \times \mathrm{LST}_{\mathrm{tn}}+\mathrm{c} \times \mathrm{LST}_{\mathrm{ad}}+\mathrm{d} \times \mathrm{LST}_{\mathrm{an}}+\mathrm{e} \times \mathrm{Ele}+\mathrm{f} \times$ Dlth $+\mathrm{g} \times \mathrm{Jd}+\mathrm{h}$,

From all of the analyses above (Pearson correlation, $\overline{\mathrm{R}}^{2}, \mathrm{BIC}$, stepwise and PCA), it is indicated that 4 LSTs $\left(\mathrm{LST}_{\mathrm{td}}, \mathrm{LST}_{\mathrm{tn}}, \mathrm{LST}_{\mathrm{ad}}, \mathrm{LST}_{\mathrm{an}}\right.$ ) play an important role in $\mathrm{T}_{\mathrm{a}-\mathrm{max}}$ and $\mathrm{T}_{\mathrm{a}-\mathrm{min}}$ estimation, because they are always included in the top models of all above-mentioned methods.

To identify which LST data $\left(\mathrm{LST}_{\mathrm{td}}, \mathrm{LST}_{\mathrm{tn}}, \mathrm{LST}_{\mathrm{ad}}, \mathrm{LST}_{\mathrm{an}}\right)$ are the best variables for $\mathrm{T}_{\mathrm{a}-\mathrm{max}}$ and

\begin{tabular}{|c|c|c|c|}
\hline \multicolumn{3}{|c|}{ Models for $\mathrm{T}_{\mathrm{a}-\max }$ Estimations $\left({ }^{*}\right)$} & Models for $\mathrm{T}_{\mathrm{a}-\mathrm{min}}$ Estimations \\
\hline 1 & $\mathrm{~T}_{\mathrm{a}-\max }=\mathrm{a} \times \mathrm{LST}_{\mathrm{tn}}+\mathrm{b}$ & 10 & $\mathrm{~T}_{\mathrm{a}-\min }=\mathrm{a} \times \mathrm{LST}_{\mathrm{an}}+\mathrm{b}$ \\
\hline 2 & $\mathrm{~T}_{\mathrm{a}-\mathrm{max}}=\mathrm{a} \times \mathrm{LST}_{\mathrm{tn}}+\mathrm{b} \times \mathrm{LST}_{\mathrm{ad}}+\mathrm{c}$ & 11 & $\mathrm{~T}_{\mathrm{a}-\mathrm{min}}=\mathrm{a} \times \mathrm{LST}_{\mathrm{tn}}+\mathrm{b} \times \mathrm{LST}_{\mathrm{an}}+\mathrm{c}$ \\
\hline 4 & $\mathrm{~T}_{\mathrm{a}-\max }=\mathrm{a} \times \mathrm{LST}_{\mathrm{td}}+\mathrm{b} \times \mathrm{LST}_{\mathrm{tn}}+\mathrm{c} \times \mathrm{LST}_{\mathrm{ad}}+\mathrm{d} \times \mathrm{LST}_{\mathrm{an}}+\mathrm{e}$ & 13 & $\mathrm{~T}_{\mathrm{a}-\mathrm{min}}=\mathrm{a} \times \mathrm{LST}_{\mathrm{td}}+\mathrm{b} \times \mathrm{LST}_{\mathrm{tn}}+\mathrm{c} \times \mathrm{LST}_{\mathrm{ad}}+\mathrm{d} \times \mathrm{LST}_{\mathrm{an}}+\mathrm{e}$ \\
\hline 5 & $\begin{array}{l}\mathrm{T}_{\mathrm{a}-\max }=\mathrm{a} \times \mathrm{LST}_{\mathrm{td}}+\mathrm{b} \times \mathrm{LST}_{\mathrm{tn}}+\mathrm{c} \times \mathrm{LST}_{\mathrm{ad}}+\mathrm{d} \times \mathrm{LST}_{\mathrm{an}}+\mathrm{e} \\
\times \text { Ele }+\mathrm{f} \times \text { Long }+\mathrm{g}\end{array}$ & 14 & $\begin{array}{l}\mathrm{T}_{\mathrm{a}-\min }=\mathrm{a} \times \mathrm{LST}_{\mathrm{td}}+\mathrm{b} \times \mathrm{LST}_{\mathrm{tn}}+\mathrm{c} \times \mathrm{LST}_{\mathrm{ad}}+\mathrm{d} \times \mathrm{LST}_{\mathrm{an}}+\mathrm{e} \\
\times \text { Dlth }+\mathrm{f} \times \mathrm{Jd}+\mathrm{g}\end{array}$ \\
\hline 7 & $\begin{array}{l}\mathrm{T}_{\mathrm{a}-\max }=\mathrm{a} \times \mathrm{LST}_{\mathrm{td}}+\mathrm{b} \times \mathrm{LST}_{\mathrm{tn}}+\mathrm{c} \times \mathrm{LST}_{\mathrm{ad}}+\mathrm{d} \times \mathrm{LST}_{\mathrm{an}}+\mathrm{e} \\
\times \text { Ele }+\mathrm{f} \times \text { Long }+\mathrm{g} \times \mathrm{Jd}+\mathrm{h} \times \mathrm{VZA}_{\mathrm{ad}}+\mathrm{i}\end{array}$ & 16 & $\begin{array}{l}\mathrm{T}_{\mathrm{a}-\min }=\mathrm{a} \times \mathrm{LST}_{\mathrm{td}}+\mathrm{b} \times \mathrm{LST}_{\mathrm{tn}}+\mathrm{c} \times \mathrm{LST}_{\mathrm{ad}}+\mathrm{d} \times \mathrm{LST}_{\mathrm{an}}+\mathrm{e} \\
\times \text { Dlth }+\mathrm{f} \times \mathrm{Jd}+\mathrm{g} \times \mathrm{Lat}+\mathrm{h} \times \text { Ele }+\mathrm{i}\end{array}$ \\
\hline 8 & $\begin{array}{l}\mathrm{T}_{\mathrm{a}-\max }=\mathrm{a} \times \mathrm{LST}_{\mathrm{td}}+\mathrm{b} \times \mathrm{LST}_{\mathrm{tn}}+\mathrm{c} \times \mathrm{LST}_{\mathrm{ad}}+\mathrm{d} \times \mathrm{LST}_{\mathrm{an}}+\mathrm{e} \\
\times \mathrm{NDVI}+\mathrm{f} \times \text { Ele }+\mathrm{g} \times \text { Long }+\mathrm{h} \times \text { Lat }+\mathrm{i} \times \mathrm{Dlth}+\mathrm{j} \times \mathrm{Jd}+ \\
\mathrm{k} \times \mathrm{VZA}_{\mathrm{td}}+1 \times \mathrm{VZA}_{\mathrm{ad}}+\mathrm{m}\end{array}$ & 17 & $\begin{array}{l}\mathrm{T}_{\mathrm{a}-\min }=\mathrm{a} \times \mathrm{LST}_{\mathrm{td}}+\mathrm{b} \times \mathrm{LST}_{\mathrm{tn}}+\mathrm{c} \times \mathrm{LST}_{\mathrm{ad}}+\mathrm{d} \times \mathrm{LST}_{\mathrm{an}}+\mathrm{e} \times \\
\mathrm{NDVI}+\mathrm{f} \times \text { Ele }+\mathrm{g} \times \text { Lat }+\mathrm{h} \times \text { Dlth }+\mathrm{i} \times \mathrm{Jd}+\mathrm{j} \times \mathrm{VZA}_{\mathrm{ad}}+\mathrm{k}\end{array}$ \\
\hline
\end{tabular}
$\mathrm{T}_{\mathrm{a} \text {-min }}$ estimation, we have tested the $\overline{\mathrm{R}}^{2}$, BIC and stepwise analysis within 4 LST product. These results gave us 4 models (Models 1-4 for $\mathrm{T}_{\mathrm{a}-\max }$, Models 10-13 for $\mathrm{T}_{\mathrm{a}-\text { min }}$ estimation) in Table 5.

Table 5. Model equations for $\mathrm{T}_{\mathrm{a}-\max }(1-9)$ and $\mathrm{T}_{\mathrm{a}-\mathrm{min}}(10-18)$ estimations.

(*): Models 1-4 and 10-13 were chosen based on analysis of 4 LST products only. Model 5-7 and 14-16 were chosen from the top 3 models of $\overline{\mathrm{R}}^{2}$ and BIC criteria. Models 8 and 17 were chosen based on stepwise analysis. Models 9 and 18 were chosen based on PCA analysis. Models 9 is also the model with all significant variables identified using Pearson correlation determination. Letters a-m are model parameters. All variables are described in Table 3. 
From Equations (3), (4), (5), (9) and (11), we build Models 5-9 for $\mathrm{T}_{\mathrm{a}-\mathrm{max}}$ estimation; Models 14-18 of $\mathrm{T}_{\mathrm{a}-\mathrm{min}}$ estimation were built based on Equations (6-8), (10) and (11).

We evaluated the models using the coefficient of determination $\left(\mathrm{r}^{2}\right)$, the root mean square error (RMSE) and the mean absolute error (MAE). Because RMSE is very sensitive to outliers, hence MAE was chosen as an additional measure of the model quality.

$$
\begin{aligned}
\operatorname{RMSE} & =\sqrt{\frac{1}{\mathrm{n}} \sum_{\mathrm{i}=1}^{\mathrm{n}}\left(\mathrm{T}_{\mathrm{a}, \mathrm{i}}-\mathrm{T}_{\mathrm{es}, \mathrm{i}}\right)^{2},} \\
\text { MAE } & =\frac{1}{\mathrm{n}} \sum_{\mathrm{i}=1}^{\mathrm{n}}\left|\mathrm{T}_{\mathrm{a}, \mathrm{i}}-\mathrm{T}_{\mathrm{es}, \mathrm{i}}\right|
\end{aligned}
$$

where $T_{a, i}$ is the observed land air surface temperature from weather stations and $T_{e s, i}$ is the corresponding land air surface temperature estimated using linear regression analysis methods.

\subsubsection{Model Calibration and Validation}

For calibration and validation purposes, all data were randomly divided into two parts: calibration and validation datasets using a $70 \% / 30 \%$ proportion, respectively.

To calculate the model coefficients a-m (see Table 5) for the models, we applied a least squares fitting analysis to the calibration dataset. The constant coefficients are listed in Appendixs A and B. To validate the models, we applied the constant coefficients, which were calculated based on the calibration dataset, to the validate dataset.

\section{Results}

\subsection{The Relationship between MODIS LST and $T_{a}$}

In order to analyze the relations between $\mathrm{T}_{\mathrm{a}}$ and all MODIS LST data, we calculated the coefficient of determination $\left(\mathrm{r}^{2}\right)$, root mean square error (RMSE) and mean absolute error (MAE) of each type of MODIS LST (TERRA daytime, TERRA nighttime, AQUA daytime and AQUA nighttime) solely with $\mathrm{T}_{\mathrm{a}}$ measured from weather stations.

Figure 3a shows that LST nighttime of both TERRA and AQUA showed a stronger correlation with $\mathrm{T}_{\mathrm{a}}$ (both $\mathrm{T}_{\mathrm{a}-\max }$ and $\mathrm{T}_{\mathrm{a}-\mathrm{min}}$ ) than for LST daytime. This can be explained by the fact that during the night, solar radiation does not affect the thermal infrared signal. Looking at the overpasses time of the satellite, the overpass time of AQUA daytime (around 1:45 p.m.) is later than the overpass time of TERRA (10:30 a.m.), as more solar radiation had been received by the land surface. As a result, LST AQUA daytime is hotter than LST TERRA daytime. Similarly, the overpass time of TERRA LST nighttime is around 10.30 p.m., three hours earlier than that of AQUA (1.45 a.m.), and the LST nighttime of TERRA is slightly higher than that of AQUA. This could be reflected by the cooling process of the land's surface at night.

It also showed that LST nighttime of TERRA seems to perform better than LST nighttime of AQUA for $\mathrm{T}_{\mathrm{a}-\mathrm{max}}$ estimation. In contrast, LST nighttime of AQUA seemed better than LST nighttime of TERRA for $\mathrm{T}_{\mathrm{a}-\mathrm{min}}$ estimation.

In order to analyze which of the four LST variables is the best suited $T_{a}$ estimation, we used the adjusted R-squared and BIC criteria (Figure 3b). Among the resulting models, we chose the one that only contained one variable. This variable is as such the best to estimate $\mathrm{T}_{\mathrm{a}}$.

It can be clearly seen that, based on the adjusted R-squared and BIC criteria (Figure 3b), the LST nighttime of TERRA and of AQUA were the best variables for $\mathrm{T}_{\mathrm{a}-\max }$ and $\mathrm{T}_{\mathrm{a} \text {-min }}$ estimation, respectively. This result was consistent with the result shown in Figure 3a.

This result also indicates that the overpass time of satellites and the time of $\mathrm{T}_{\mathrm{a}-\mathrm{max}}, \mathrm{T}_{\mathrm{a}-\mathrm{min}}$ recorded had no key influence on the relationship between $T_{a}$ and LST. This is consistent with other research $[8,25]$. 

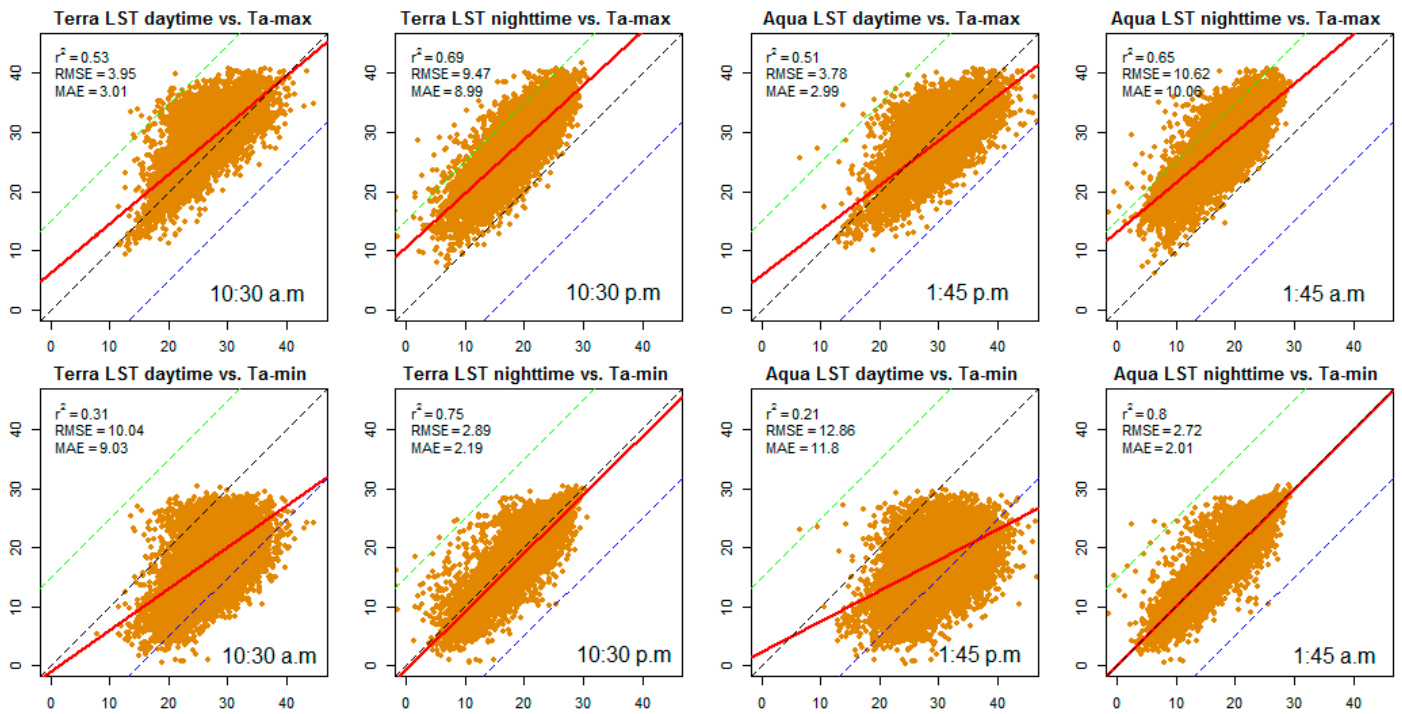

(a)

Adjusted R-squared - Tamax

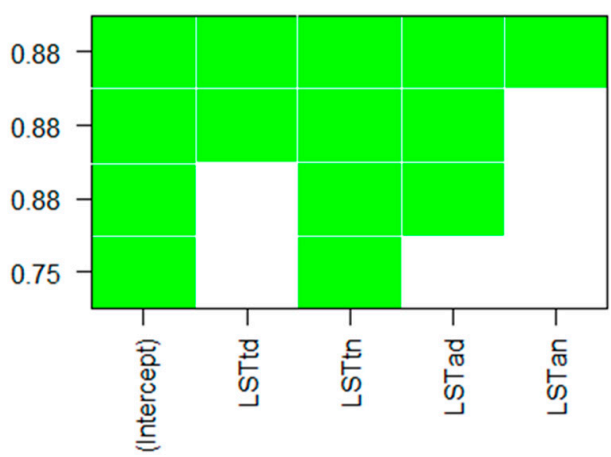

Adjusted R-squared - Tamin

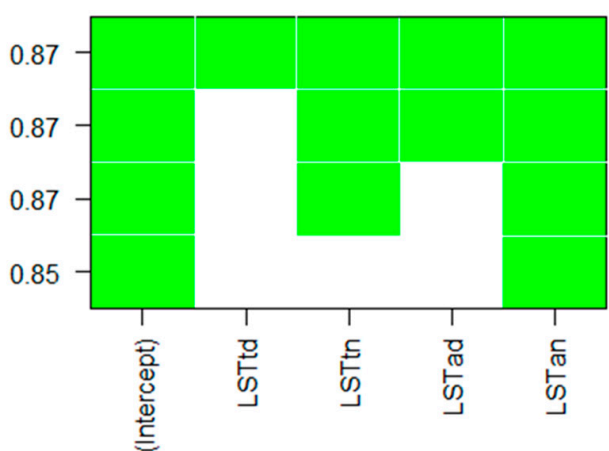

BIC - Tamax

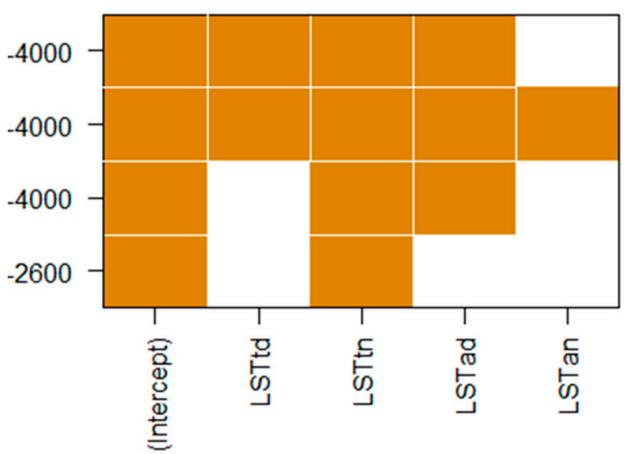

BIC - Tamin

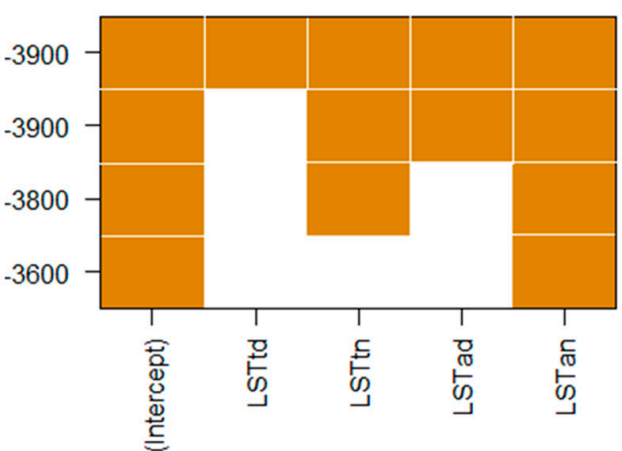

(b)

Figure 3. (a) The relationship between LST (x-axis) and $\mathrm{T}_{\mathrm{a}-\mathrm{max}}$ (upper panels), $\mathrm{T}_{\mathrm{a}-\mathrm{min}}$ (lower panels) of all meteorological stations from 2003-2013. The dashed green line indicates that the difference between $\mathrm{T}_{\mathrm{a}}$ and LST is over $+15^{\circ} \mathrm{C}$; the dashed blue line indicates that the difference between $\mathrm{T}_{\mathrm{a}}$ and LST is lower than $-15^{\circ} \mathrm{C}$. The dashed black line indicates the 1:1 line. The solid red line shows the regression line. (b) Adjusted R-squared and BIC criteria show the top four models of $\mathrm{T}_{\mathrm{a}-\mathrm{max}}$ (upper panel) and $\mathrm{T}_{\mathrm{a}-\mathrm{min}}$ (lower panel) estimation using only the four LST dataset. 


\subsection{Ta-Max Estimation}

The parameters of models for $\mathrm{T}_{\mathrm{a}-\mathrm{max}}$ estimation were determined when we applied Models 1-9 to the calibration dataset. This result is shown in Appendix A.

Figure 4 show that the results of the nine models were consistent with the processing in Section 2.5. Model 1 showed the lowest result, followed by Models 2-4.

Models 5-8 presented similar high results. However, Model 5 used only six variables; Models 6, 7 and 8 used 7, 8 and 12 variables, respectively. Based on this point, Model 5 would be chosen as the best model of $\mathrm{T}_{\mathrm{a}-\mathrm{max}}$ estimation.

Combining LST TERRA nighttime and LST AQUA daytime (Model 2), the result of $\mathrm{T}_{\mathrm{a}-\mathrm{max}}$ estimation was significantly better than Model 1 using LST TERRA nighttime solely. However, when we added LST TERRA daytime (Model 3, three variables), LST TERRA daytime and LST AQUA nighttime (Model 4, four variables), the performance of these models was not significantly improved in comparison to Model 2 (using two variables).

Comparing Model 4 and Model 5, it can be seen that, by combining four LSTs and elevation (Ele), longitude (Long) into the model, the result was much higher than using four LSTs only. This indicates that elevation (Ele), as well as the location (Long) of the weather station play an important role in $\mathrm{T}_{\mathrm{a}-\mathrm{max}}$ estimation.
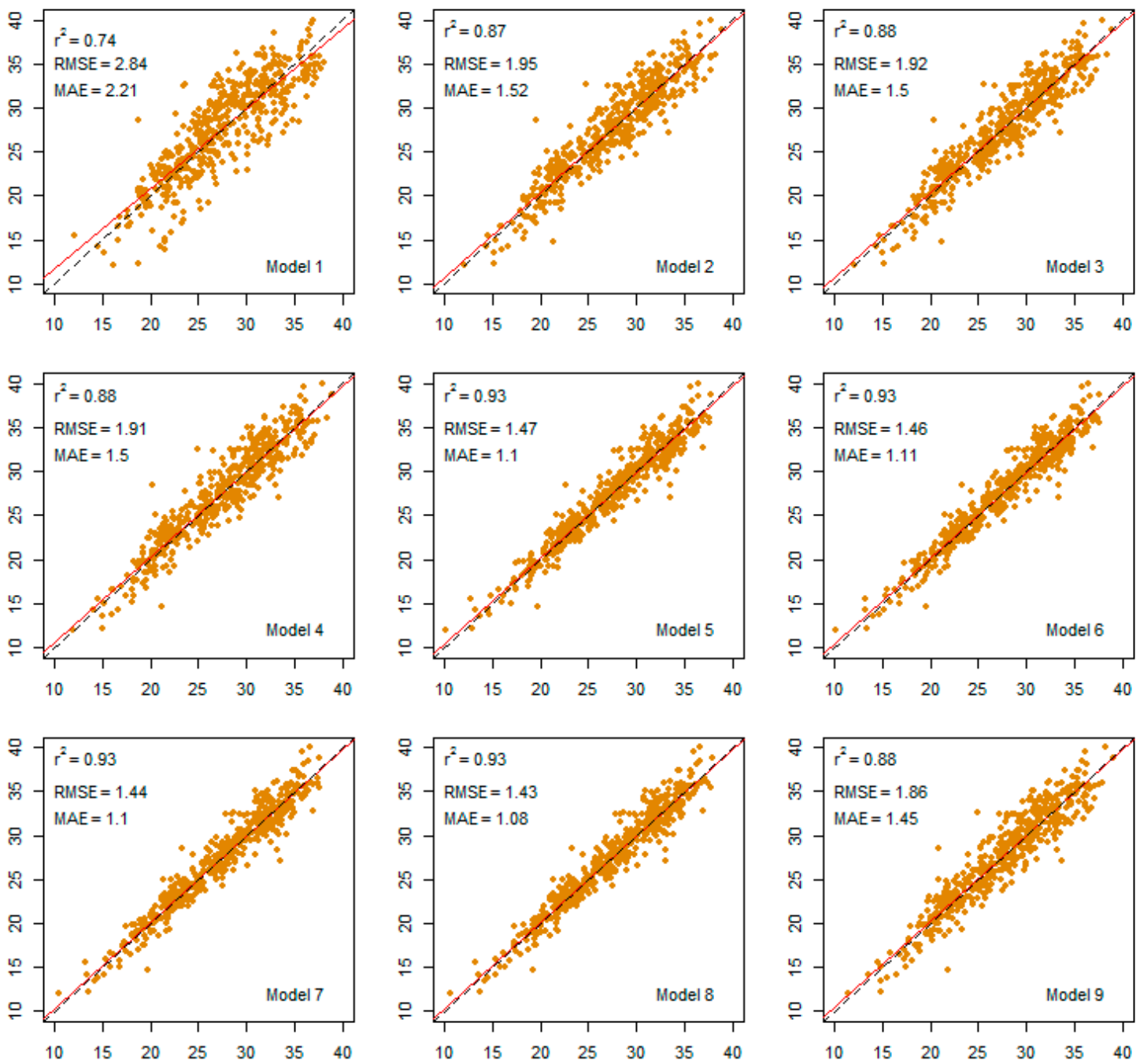

Figure 4. The relationship between $T_{a}$ observed (y-axis) and $T_{a}$ estimated (x-axis) using Models 1-9. The dashed black line indicates the 1:1 line. The solid red line shows the regression line. 


\subsection{Ta-Min Estimation}

The parameters of models for $\mathrm{T}_{\mathrm{a}-\mathrm{min}}$ estimation were determined when we applied Models 10-18 to the calibration dataset. This result is shown in Appendix B.

In general, Figure 5 shows that all models gave similar results of $\mathrm{T}_{\mathrm{a}-\mathrm{min}}$ estimation. From the simple model with two variables to the complex model (Model 17) using 10 variables, the results are similar. Figure 5 also shows that $\mathrm{T}_{\mathrm{a}-\mathrm{min}}$ estimation can reach a very high accuracy $\left(\mathrm{r}^{2}=0.85\right.$, RMSE $=2.31, \mathrm{MAE}=1.75$ ) when using only one variable: $\mathrm{LST}_{\mathrm{an}}$. However, it was difficult to increase the accuracy of $\mathrm{T}_{\mathrm{a}-\mathrm{min}}$ estimated even with 10 variables or all 14 variables (see Figure 5).
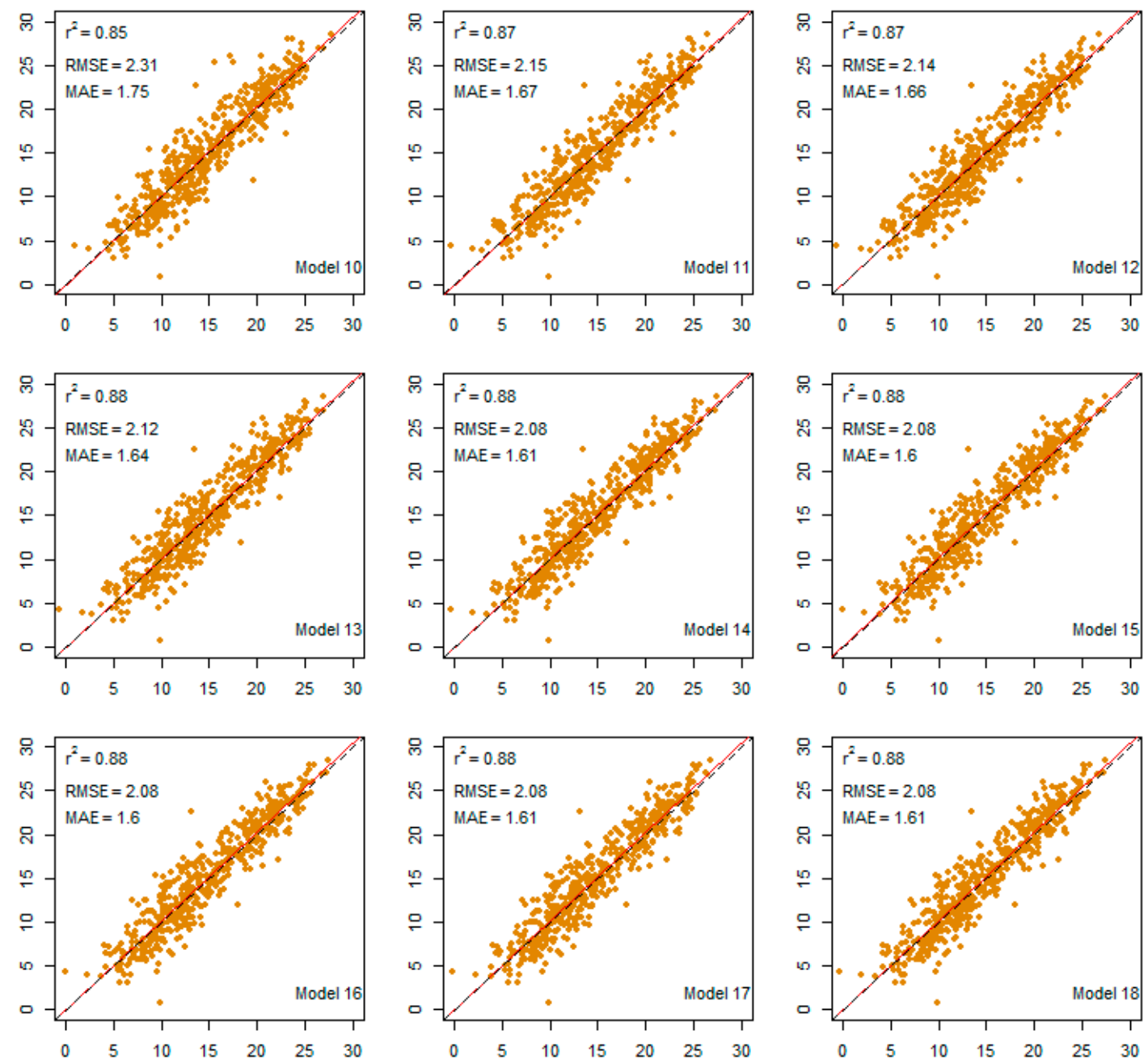

Figure 5. The relationship between $\mathrm{T}_{\mathrm{a}}$ observed (y-axis) and $\mathrm{T}_{\mathrm{a}}$ estimated (x-axis) using Models 10-18.

The dashed black line indicates the 1:1 line. The solid red line shows the regression line.

\subsection{Performance of the Best Model}

In order to test the effect of weather station location, as well as the seasonal change or any other factor related to station characteristics, we applied the best model to all datasets. The results are shown in Figure 6.

Looking at Figures 4-6, it can be clearly seen that there are similar results of Model 5 and Model 15 when we applied them to the validation dataset or to all datasets. This consistent result indicates that there is no significant factor that could affect the accuracy of $\mathrm{T}_{\mathrm{a}}$ estimation when Model 5 and Model 15 were applied for $\mathrm{T}_{\mathrm{a}-\max }$ and $\mathrm{T}_{\mathrm{a}-\min }$ estimation, respectively. 

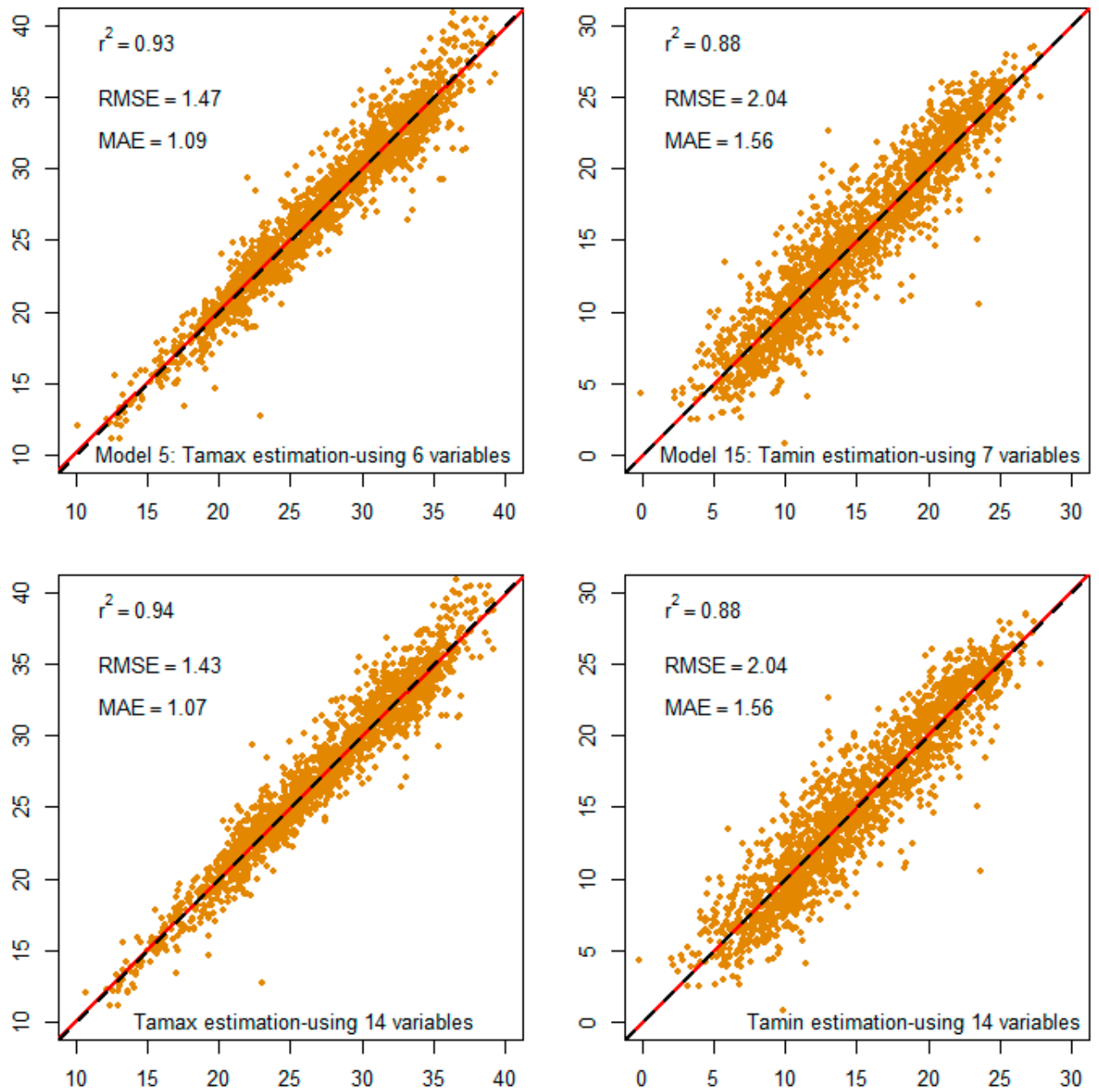

Figure 6. The comparison of estimated $\mathrm{T}_{\mathrm{a}}$ using Model 5, Model 15 and the model using 14 variables. The dashed black line indicates the 1:1 line. The solid red line shows the regression line.

\section{Discussion}

\subsection{MODIS LST Products for $T_{a}$ Estimation}

There are two MODIS sensors, TERRA and AQUA, which provides LST data four times daily (i.e., $\mathrm{LST}_{\mathrm{td}}, \mathrm{LST}_{\mathrm{tn}}, \mathrm{LST}_{\mathrm{ad}}, \mathrm{LST}_{\mathrm{an}}$ ). Most previous studies have used LST daytime for $\mathrm{T}_{\mathrm{a}-\mathrm{max}}$ and $\mathrm{LST}$ nighttime for $\mathrm{T}_{\mathrm{a}-\mathrm{min}}$ estimation. Some studies used only TERRA MODIS LST for $\mathrm{T}_{\mathrm{a}}$ estimation $[45,46]$. There is a handful studies using LST daytime for $\mathrm{T}_{\mathrm{a}-\mathrm{min}}$ and LST nighttime for $\mathrm{T}_{\mathrm{a}-\mathrm{max}}$ estimation $[29,42]$.

As far as we know, there have also been several studies using both LST daytime and nighttime of both MODIS sensors on TERRA and AQUA for their $T_{a}$ estimated models $[15,33,42,60]$. However, the purpose of using four times daily LST was for filling the missing LST value. In our study, it is required that all four LST data have to be available.

Zhang et al. [42] combine TERRA LST daytime and nighttime (two variables), AQUA LST daytime and nighttime (also two variables) for $\mathrm{T}_{\mathrm{a}}$ estimation and concluded that: (i) nighttime LST was better than daytime for deriving daily $\mathrm{T}_{\mathrm{a}}$; and (ii) incorporating daytime and nighttime LST significantly improved the estimation of $T_{a}$, as compared to using LST nighttime or daytime solely. Our results were consistent with this study [42]; however, our analysis could provide an even deeper insight into the matter. Model 2 and Figure 3b show that the combination of TERRA LST nighttime and AQUA LST daytime is even better than that of TERRA LST daytime and TERRA LST nighttime. 
For $\mathrm{T}_{\mathrm{a}-\mathrm{max}}$ estimation, Figure 4 shows that if only LST products are used (without auxiliary data) the best result was achieved when we combined all four LST data (model 4). However, the Model 4 result (using four LSTs) was just slightly better than Model 2 (using only $\mathrm{LST}_{\mathrm{tn}}$ and $\mathrm{LST}_{\mathrm{ad}}$ ).

Similarly, the best result of $\mathrm{T}_{\mathrm{a}-\mathrm{min}}$ estimation was achieved when we combined all four LSTs (Model 13). The combination of $\mathrm{LST}_{\mathrm{tn}}$ and $\mathrm{LST}_{\mathrm{an}}$ (Model 11) made the result of $\mathrm{T}_{\mathrm{a}-\mathrm{min}}$ estimation better than using LST $_{\text {an }}$ solely (Model 10).

As we can see from Figure 2, $\mathrm{T}_{\mathrm{a}-\mathrm{min}}$ has a stronger correlation with LST nighttime of both TERRA and AQUA than $\mathrm{T}_{\mathrm{a}-\mathrm{max}}$. However, as the final result, $\mathrm{T}_{\mathrm{a}}$ estimation and $\mathrm{T}_{\mathrm{a}-\mathrm{max}}$ estimation show a much higher accuracy than $\mathrm{T}_{\mathrm{a}-\mathrm{min}}$.

\subsection{Effect of Seasonal on the Accuracy of $T_{a}$ Estimation}

To examine the effect of seasons on the relationship between LST and $\mathrm{T}_{\mathrm{a}}\left(\mathrm{T}_{\mathrm{a}-\mathrm{max}}\right.$ and $\left.\mathrm{T}_{\mathrm{a}-\mathrm{min}}\right)$, we separated the data into four seasons: spring (March, April, May), summer (June, July, August), autumn (September, October, November) and winter (December, January, February).

Looking at the nine upper panels ( $\mathrm{T}_{\mathrm{a}-\mathrm{max}}$ estimation) of Figure 7 , it can be seen that the accuracy of $\mathrm{T}_{\mathrm{a} \text {-max }}$ estimation was significantly improved through different models. Models 1, 2, 3 and 4 show a low accuracy of $\mathrm{T}_{\mathrm{a}-\mathrm{max}}$ estimated in summer. Models 5, 6, 7 and 8 show a similar accuracy of $\mathrm{T}_{\mathrm{a} \text {-max }}$ estimation. Model 9 again shows a low accuracy in summer. This means that, if we estimate $\mathrm{T}_{\mathrm{a}}$-max using LST data without other auxiliary data, the results would not be accurate. This can be explained by, as in the summer, the land surface receiving more solar radiation, and as such, the relation between $\mathrm{T}_{\mathrm{a}}$ and LST becomes more complex.

In general, the changing season had no significant effect on the accuracy of $\mathrm{T}_{\mathrm{a}}$ estimation if we use all four LST data and other variables for linear regression.

\subsection{Effect of View Zenith Angle on the Accuracy of $T_{a}$ Estimation}

As mentioned in Section 2.4, LST data were collected at smaller viewing zenith angles or LST retrievals at larger zenith angles, but with LST errors smaller than at least $2 \mathrm{~K}$.

In order to check the effect of VZA on the relationship between MODIS LST and $\mathrm{T}_{\mathrm{a}}$, we divided the data into three groups based on the range of VZA: bl40 $\left(0^{\circ} \leq \mathrm{VZA} \leq 40^{\circ}\right)$, f41t90 $\left(41^{\circ} \leq \mathrm{VZA} \leq 90^{\circ}\right)$ and f91t130 $\left(91^{\circ} \leq \mathrm{VZA} \leq 130^{\circ}\right)$. Using all linear regression models in Table 5 for $\mathrm{T}_{\mathrm{a} \text {-max }}$ and $\mathrm{T}_{\mathrm{a} \text {-min }}$ estimation, we then calculated the difference between $T_{a}$ estimated and $T_{a}$ measured (difference $=$ $T_{a}$ measured $-T_{a}$ estimated). These differences are shown in Figure 8. Although the differences might vary from Models 1-9 of $\mathrm{T}_{\mathrm{a}-\mathrm{max}}$ estimation and Models 10-18 of $\mathrm{T}_{\mathrm{a}-\mathrm{min}}$ estimation, it was similar between the three groups through all models. This indicates that the effect of VZA on the result of $T_{a}$ estimation was not significant.

\subsection{Effect of Station Elevation on Accuracy}

To test the effect of weather station elevation on the estimation results, we divided the data into three regions: bl200m, f200t500m and ov500m. The bl200m region includes stations that have an elevation below $200 \mathrm{~m}$; the $\mathrm{f} 200 \mathrm{t} 500 \mathrm{~m}$ region includes stations having an elevation from $200-500 \mathrm{~m}$; and ov500m region includes stations that have an elevation higher than $500 \mathrm{~m}$. It should be noted that this division is just one option to test the effect of station altitude that might affect the results. It could be divided into more parts for more detail (the more parts are divided, the more detail on the differences could be achieved). We calculated the difference between $T_{a}$ estimated and $T_{a}$ measured of these three groups of elevation (difference $=T_{a}$ measured $-T_{a}$ estimated). These differences are shown in Figure 9.

As we can see in Figure 9, for $\mathrm{T}_{\mathrm{a} \text {-max }}$, the differences of three groups were variations from Models 1-9. The most significant was found in Model 1 and Model 9. Models 5, 6, 7 and 8 showed a similar difference between three groups. This indicates that we can reduce the effect of the station's elevation by using Model 5, 6, 7 or 8 . 
Looking at Table 5, we found that all of Models 5, 6, 7 and 8 include longitude and elevation variable in the models. Model 9 also has the elevation variable in it, but Figure 9 shows that there is a difference between the three elevation groups. It could be concluded that the longitude variable affects the $\mathrm{T}_{\mathrm{a}-\mathrm{max}}$ estimation.

Regarding $\mathrm{T}_{\mathrm{a}-\mathrm{min}}$ estimation, Figure 9 shows a similar result of all models (from Models 10-18) and a similar performance between the three elevation groups. This indicates that the station's elevation has no effect on $\mathrm{T}_{\mathrm{a}-\mathrm{min}}$ estimation.
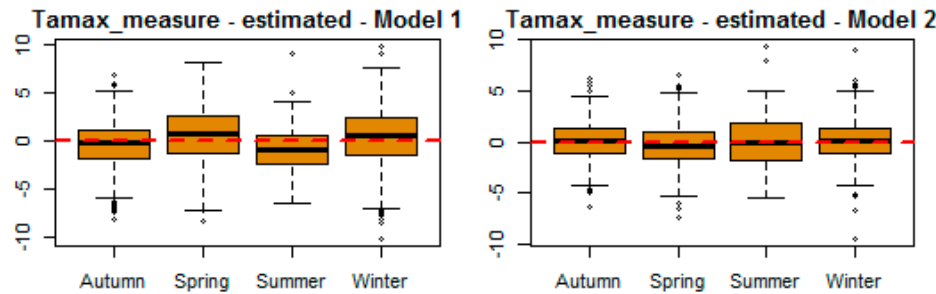

Tamax_measure - estimated - Model 3

Tamax_measure - estimated - Model 4

Tamax_measure - estimated - Model 5
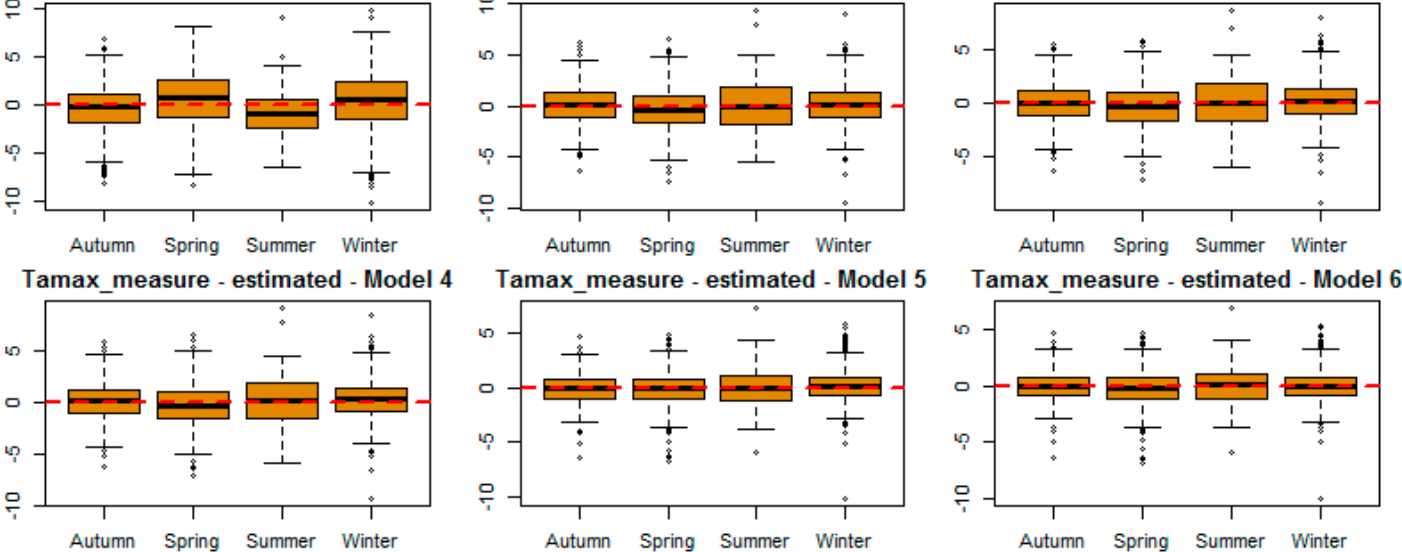

Tamax measure - estimated - Model 6

amax_measure - estimated - Model 7

Tamax_measure - estimated - Model 8
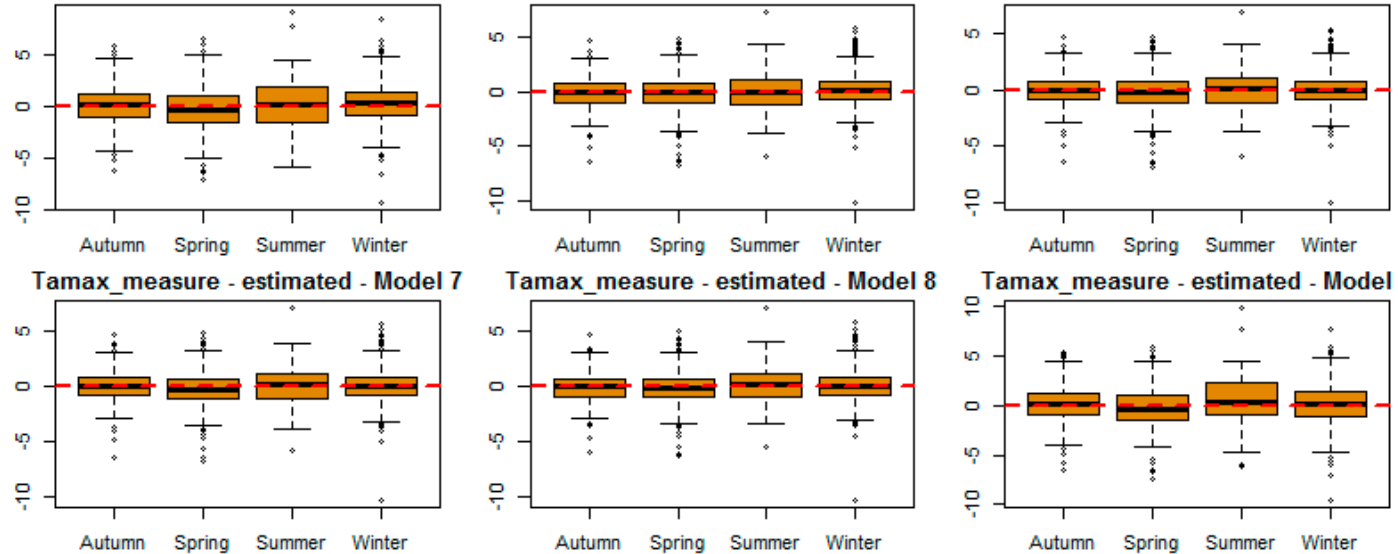

Tamax_measure - estimated - Model 9

amin_measure - estimated - Model 10

Tamin measure - estimated - Model 11
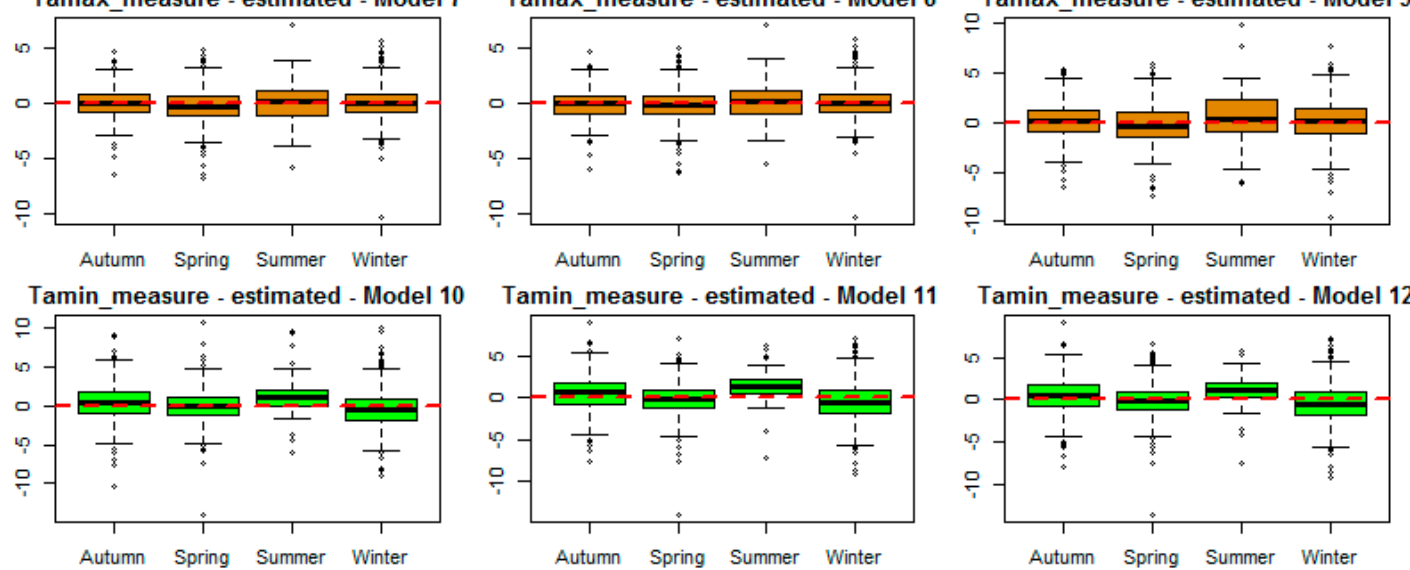

Tamin measure - estimated - Model 12

min_measure - estimated - Model 14

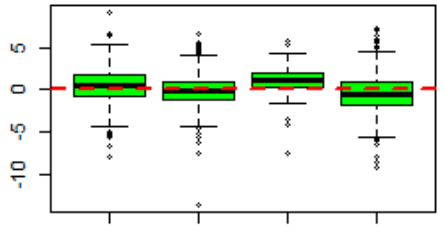

Tamin_measure - estimated - Model 13

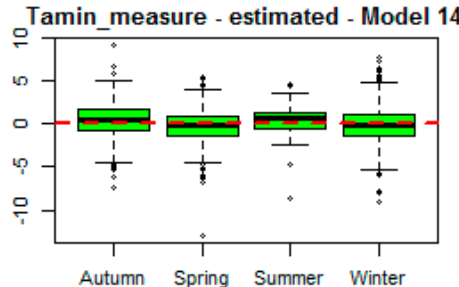

Autumn Spring Summer Winter

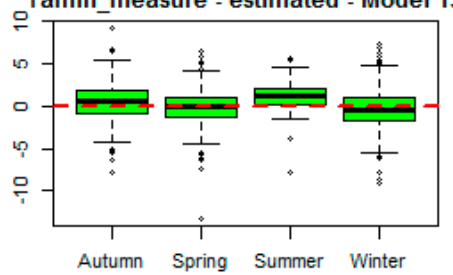

min measure - estimated - Model 17

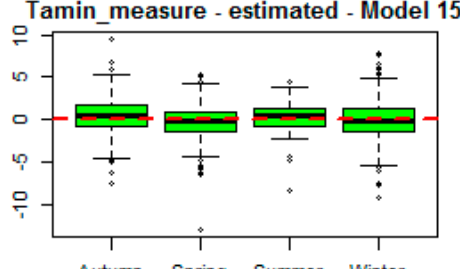

Tamin_measure - estimated - Model 16
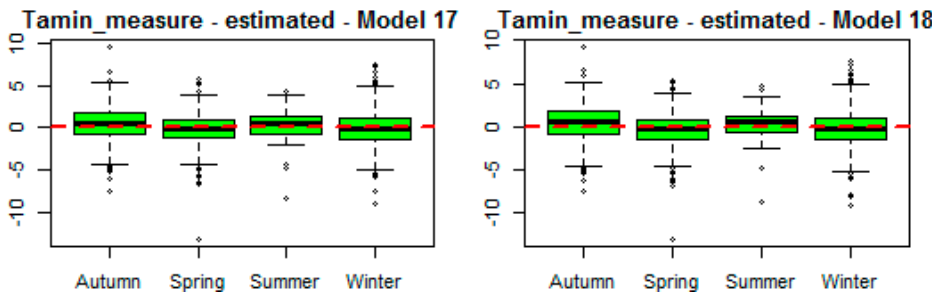

Figure 7. Box-plots with the difference between $\mathrm{T}_{\mathrm{a}}$-estimated and $\mathrm{T}_{\mathrm{a}}$-measured by season in years. The line within the box indicates the median. The bottom of the box is the first quartile, and the top is the third quartile. Whiskers represent the lowest value still within 1.5 IQR (IQR = third quartile - first quartile) and the highest value still within 1.5 IQR. The black plus mark indicates the outliers. 

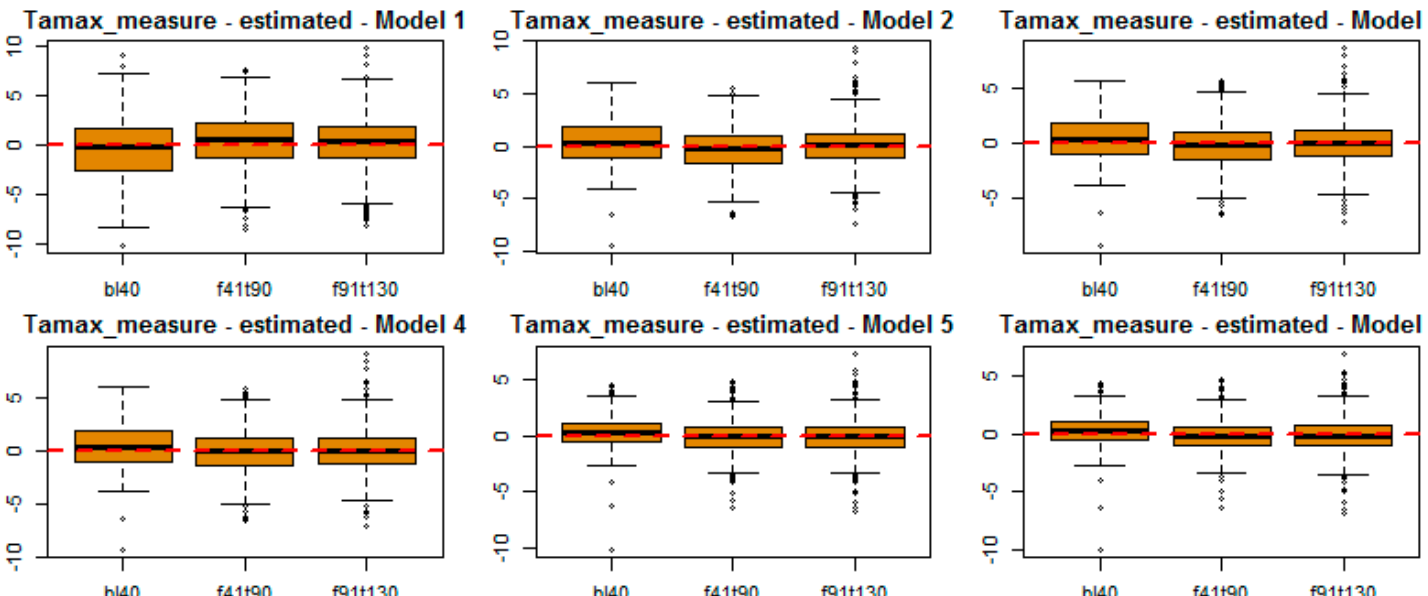

Tamax measure - estimated - Model 5

Tamax_measure - estimated - Model 6
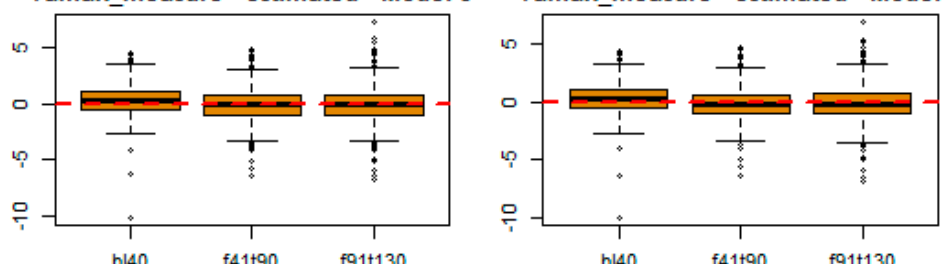

Tamax_measure - estimated - Model 7

Tamax_measure - estimated - Model 8

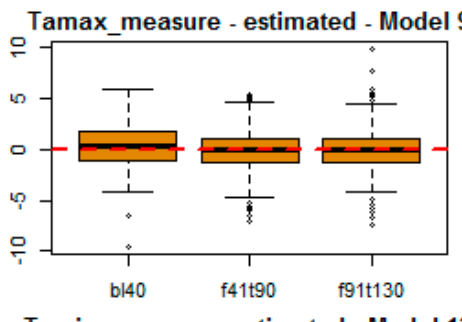

bl40 f41t90 f91t130

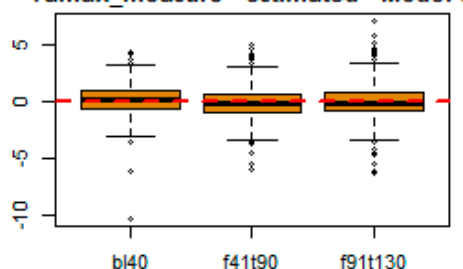

Tamin measure - estimated - Model 10

Tamin measure - estimated - Model 11

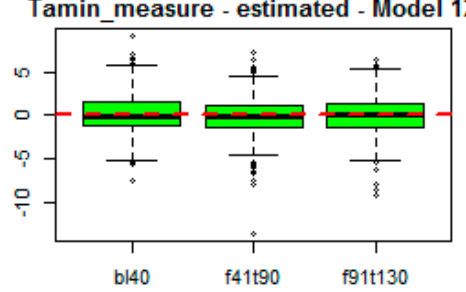

bl40 f41t90 f91t130

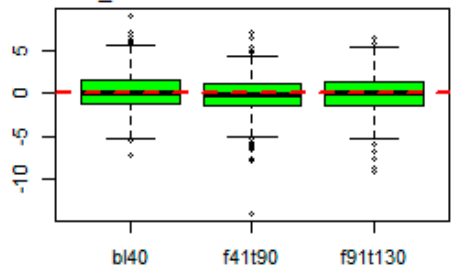

Tamin_measure - estimated - Model 13

Tamin_measure - estimated - Model 14

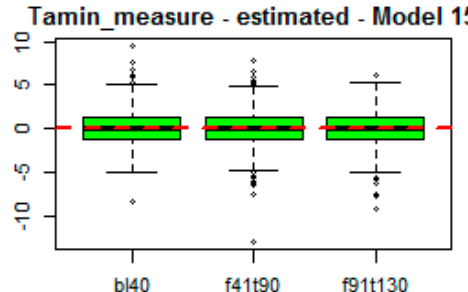

f41t90 f91t130
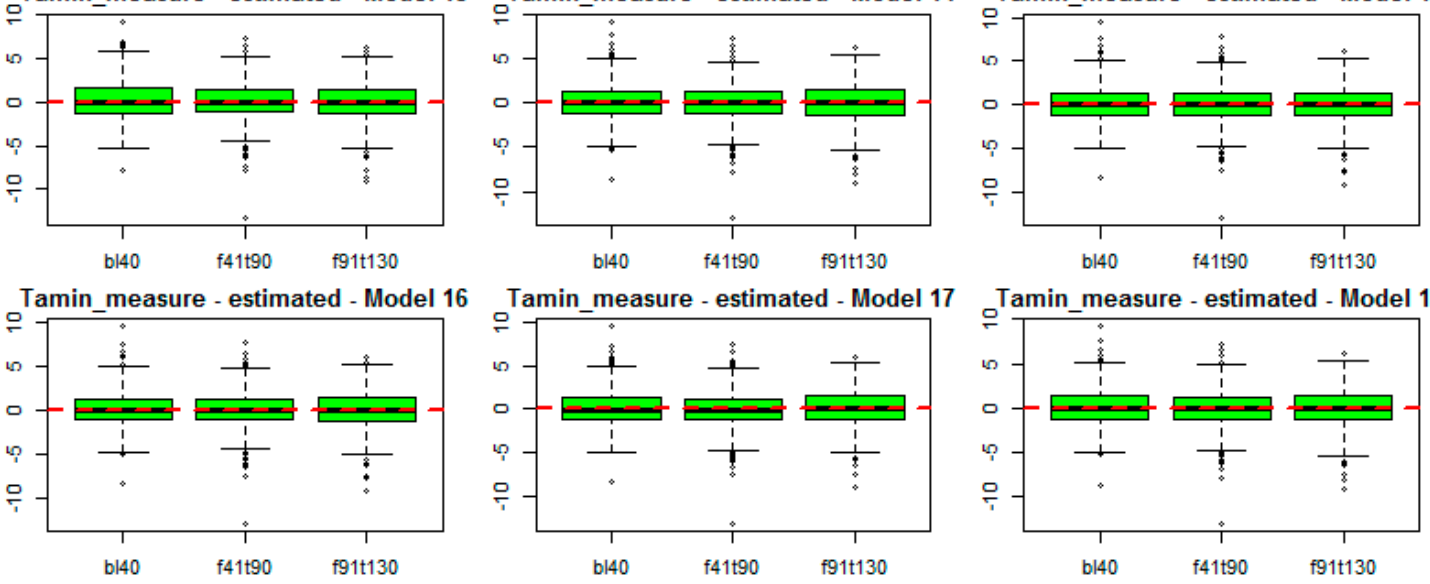

Figure 8. Box-plots with the difference between $\mathrm{T}_{\mathrm{a}}$-estimated and $\mathrm{T}_{\mathrm{a}}$-measured by the view zenith angle (VZA). The line within the box indicates the median. The bottom of the box is the first quartile, and the top is the third quartile. Whiskers represent the lowest value still within 1.5 IQR (IQR = third quartile - first quartile) and the highest value still within $1.5 \mathrm{IQR}$. The black plus mark indicates outliers. bl40 $\left(0^{\circ} \leq \mathrm{VZA} \leq 40^{\circ}\right)$, f41t90 $\left(41^{\circ} \leq \mathrm{VZA} \leq 90^{\circ}\right)$, f91t130 $\left(91^{\circ} \leq \mathrm{VZA} \leq 130^{\circ}\right)$. 

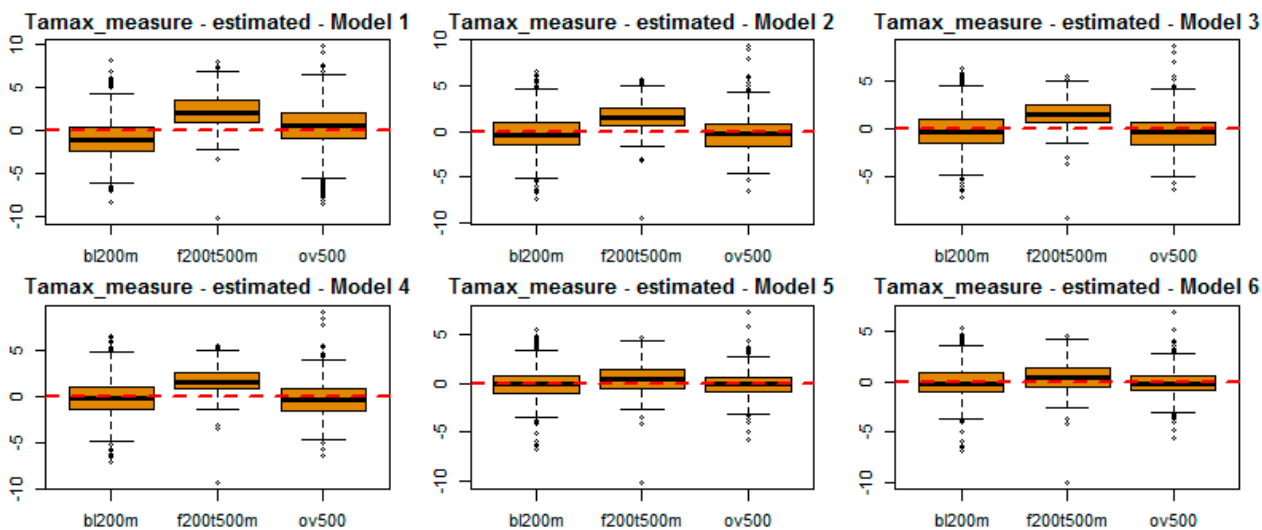

Tamax measure - estimated - Model 5

Tamax_measure - estimated - Model 6
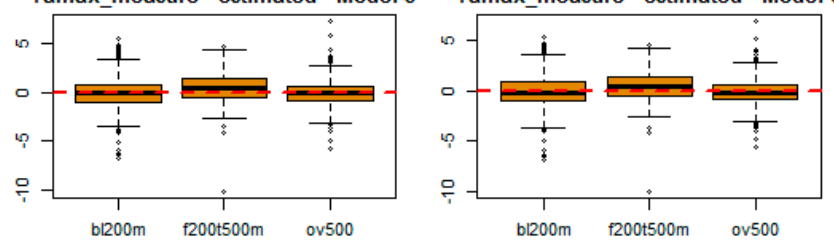

Tamax_measure - estimated - Model 7

Tamax_measure - estimated - Model 8

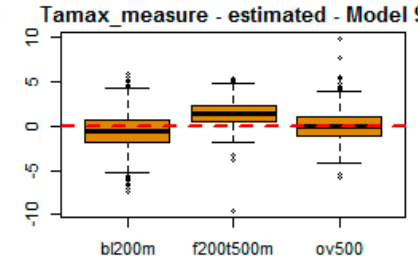

Tamin_measure - estimated - Model 10
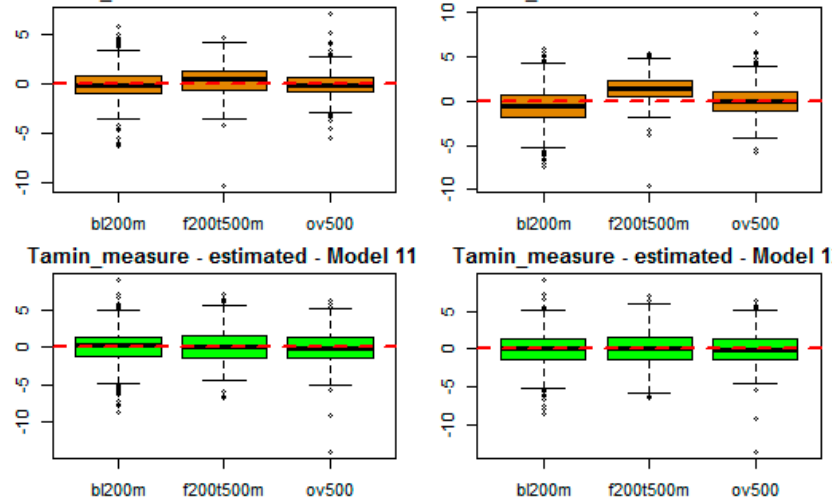

bl200m f200t500m ov500
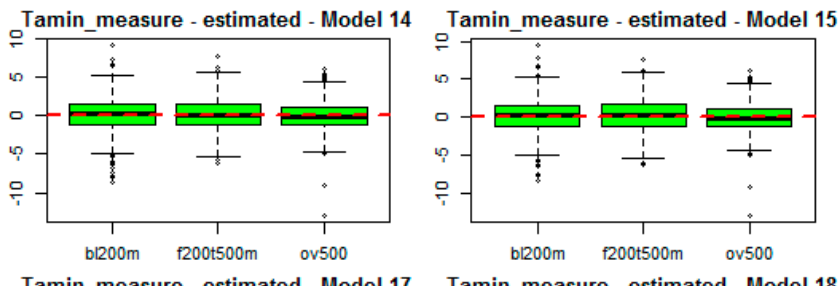

Tamin_measure - estimated - Model 13
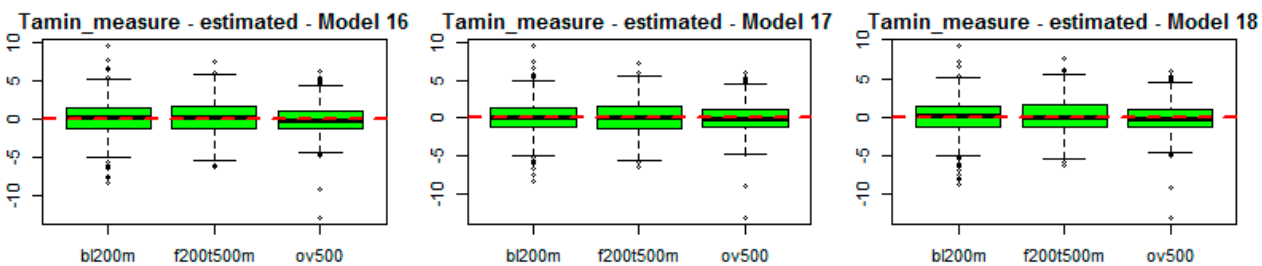

Figure 9. Box-plots with the difference between $\mathrm{T}_{\mathrm{a}}$-estimated and $\mathrm{T}_{\mathrm{a}}$-measured by the elevation of the station (Ele). The line within the box indicates the median. The bottom of the box is the first quartile, and the top is the third quartile. Whiskers represent the lowest value still within $1.5 \mathrm{IQR}$ (IQR = third quartile - first quartile) and the highest value still within $1.5 \mathrm{IQR}$. The black plus mark indicates outliers. bl200m (Ele < $200 \mathrm{~m})$, f200t500 (200 m $\leq$ Ele $\leq 500 \mathrm{~m})$, ov500 (Ele > $500 \mathrm{~m}$ ).

\subsection{Accuracy Improvement by Integrating Four LST Products and Auxiliary Variables}

\subsubsection{For $\mathrm{T}_{\mathrm{a}-\mathrm{max}}$ Estimation}

When comparing the results of Model 4 (using four LST data) versus Models 5-9 (using four LST data and auxiliary data; see Figure 4), it can be clearly seen that the results were significantly improved. The coefficient of determination $\left(\mathrm{r}^{2}\right)$ was increased from 0.88-0.93; RMSE and MAE were decreased from 1.91 down to 1.43 and 1.50 down to $1.08{ }^{\circ} \mathrm{C}$ respectively.

The performances of Models 5, 6 and 7 were similar and had very high accuracy. As shown in the variable selection section (Section 2.5.1), these models came from the top three models of adjusted R-squared and BIC criteria. 
Model 8, which was chosen from stepwise regression, showed a similar result of accuracy. However, this model used up to 12 variables.

Model 9, which was chosen based on PCA analysis, also showed a high accuracy result with $r^{2}=0.88$, RMSE $=1.86$, and MAE $=1.45$; however, this result was not as high as the results of Models 5, 6,7 , and 8 .

Looking at Table 5, it can be clearly seen that Models 5-8 always include elevation and longitude variables. It would be expected that because Model 9 did not use the longitude variable, therefore the accuracy was not as good as Models 5, 6, 7 and 8.

This indicates that elevation and longitude are the most important variables for $\mathrm{T}_{\mathrm{a} \text {-max }}$ estimation. This result is consistent with adjusted R-squared, BIC criteria and stepwise analysis.

\subsubsection{For $\mathrm{T}_{\mathrm{a}-\mathrm{min}}$ Estimation}

Looking at Figure 5, it can be clearly seen that the results of all nine models (Models 10-18) were not significantly different. In other words, the accuracy of the model was not increased from the simplest (Model 10, using one variable) to the most complex model (Model 17 with 10 variables).

In comparison to previous studies (see Table 1), we achieved better results (similar $\mathrm{r}^{2}$, but smaller RMSE and MAE) of $\mathrm{T}_{\mathrm{a}-\mathrm{max}}$ estimation due to the combination of four LST data and auxiliary variables. However, this combination just made a slight improvement for the $\mathrm{T}_{\mathrm{a}-\mathrm{min}}$ estimation (comparing the result of Model 10, versus Models 11-18). In a further study, a better method for increasing the accuracy of $\mathrm{T}_{\mathrm{a}-\mathrm{min}}$ estimation should be examined.

Considering the coefficient of determination $\left(\mathrm{r}^{2}\right)$, the accuracy (RMSE, MAE) and the number of variables used per model, we would regard Model 5 (for $\mathrm{T}_{\mathrm{a} \text {-max }}$ estimation) and Model 15 (for $\mathrm{T}_{\mathrm{a}-\text { min }}$ estimation) as the best models.

\section{Conclusions}

In this study, we have analyzed and discussed the relationship between $\mathrm{T}_{\mathrm{a}-\mathrm{max}}, \mathrm{T}_{\mathrm{a}-\mathrm{min}}$ and four LST products $\left(\mathrm{LST}_{\mathrm{td}}, \mathrm{LST}_{\mathrm{tn}}, \mathrm{LST}_{\mathrm{ad}}, \mathrm{LST}_{\mathrm{an}}\right)$. The simple method of multiple linear regression analysis was used, and a high accuracy was achieved with $\mathrm{r}^{2}=0.93$, RMSE $=1.43, \mathrm{MAE}=1.08$ and $\mathrm{r}^{2}=0.88$, RMSE $=2.08, \mathrm{MAE}=1.60$, for $\mathrm{T}_{\mathrm{a}-\max }$ and $\mathrm{T}_{\mathrm{a}-\mathrm{min}}$, respectively.

When estimating $T_{a}$ using one LST datum solely, $T_{a-m i n}$ showed a better result than $T_{a-m a x}$ (Model 1 versus Model 10 in Figures 4 and 5). Multiple linear regressions always give better results than simple linear.

An interesting result is that when we directly compared LST data versus $T_{a}$, LST nighttime showed a stronger correlation with both $\mathrm{T}_{\mathrm{a}-\max }$ and $\mathrm{T}_{\mathrm{a} \text {-min }}$ than LST daytime; $\mathrm{T}_{\mathrm{a} \text {-min }}$ had a better correlation with LST data than $\mathrm{T}_{\mathrm{a}-\max }$ (see Figure 3a). However, the results of modeling showed that $\mathrm{T}_{\mathrm{a}-\mathrm{max}}$ can be estimated with better results (higher $\mathrm{r}^{2}$ and lower RMSE, MAE) than $\mathrm{T}_{\mathrm{a} \text {-min }}$ when adding auxiliary variables into the models. It could be concluded that in $T_{a}$ estimation, it is not possible to see the relationship between $T_{a}$ and LST from a directed comparison, because there are other factors that also affect that relationship.

Several model analyses indicate that MODIS LST represents the most important variables for $T_{a}$ estimation. However, to achieve the best results, other variables, such as day length (in hours), Julian day, longitude, latitude and elevation, should be taken into consideration and put into the models.

Acknowledgments: We would like to acknowledge the Vietnamese Government for their financial supported and the Vietnam Institute of Meteorology, Hydrology and ENvironment (IMHEN) for supplying the meteorological data for this research. We thank the Open Access Publication Funds of Göttingen University. We also thank the journal's anonymous reviewers for their valuable comments, which greatly improved our paper.

Author Contributions: The second author conceived of and designed the statistical analysis. The first author analyzed the data and performed the experiments. The third author contributed analysis tools. All authors together developed and wrote the paper.

Conflicts of Interest: The authors declare no conflict of interest. 


\section{Appendix A}

Table A1. Parameters of Models for $\mathrm{T}_{\mathrm{a}-\max }$ Estimation.

\begin{tabular}{|c|c|c|c|c|c|}
\hline & & Estimate & Std. Error & $t$-Value & $p$-Value \\
\hline \multirow{2}{*}{ Model 1} & (Intercept) & 10.7057 & 0.2954 & 36.2400 & 0.0000 \\
\hline & $\mathrm{LST}_{\mathrm{tn}}$ & 0.9826 & 0.0165 & 59.7200 & 0.0000 \\
\hline \multirow{3}{*}{ Model 2} & (Intercept) & 2.1651 & 0.3159 & 6.8530 & 0.0000 \\
\hline & $\mathrm{LST}_{\mathrm{tn}}$ & 0.5778 & 0.0161 & 35.8360 & 0.0000 \\
\hline & $\mathrm{LST}_{\mathrm{ad}}$ & 0.5133 & 0.0145 & 35.4500 & 0.0000 \\
\hline \multirow{4}{*}{ Model 3} & (Intercept) & 1.8313 & 0.3206 & 5.7110 & 0.0000 \\
\hline & $\mathrm{LST}_{\mathrm{td}}$ & 0.1234 & 0.0258 & 4.7810 & 0.0000 \\
\hline & $\mathrm{LST}_{\mathrm{tn}}$ & 0.5482 & 0.0171 & 32.0060 & 0.0000 \\
\hline & $\mathrm{LST}_{\mathrm{ad}}$ & 0.4329 & 0.0221 & 19.5830 & 0.0000 \\
\hline \multirow{5}{*}{ Model 4} & (Intercept) & 1.7664 & 0.3226 & 5.4750 & 0.0000 \\
\hline & $\mathrm{LST}_{\mathrm{td}}$ & 0.1283 & 0.0259 & 4.9470 & 0.0000 \\
\hline & $\mathrm{LST}_{\mathrm{tn}}$ & 0.6028 & 0.0363 & 16.6280 & 0.0000 \\
\hline & $\mathrm{LST}_{\mathrm{ad}}$ & 0.4305 & 0.0221 & 19.4510 & 0.0000 \\
\hline & $\mathrm{LST}_{\mathrm{an}}$ & -0.0570 & 0.0334 & -1.7080 & 0.0880 \\
\hline \multirow{7}{*}{ Model 5} & (Intercept) & 265.4000 & 9.1650 & 28.9520 & 0.0000 \\
\hline & $\mathrm{LST}_{\mathrm{td}}$ & 0.1646 & 0.0197 & 8.3610 & 0.0000 \\
\hline & $\mathrm{LST}_{\mathrm{tn}}$ & 0.5297 & 0.0274 & 19.3710 & 0.0000 \\
\hline & $\mathrm{LST}_{\mathrm{ad}}$ & 0.2505 & 0.0176 & 14.2410 & 0.0000 \\
\hline & $\mathrm{LST}_{\mathrm{an}}$ & 0.1419 & 0.0260 & 5.4600 & 0.0000 \\
\hline & Ele & -0.0028 & 0.0001 & -19.8260 & 0.0000 \\
\hline & Long & -2.4810 & 0.0865 & -28.6960 & 0.0000 \\
\hline \multirow{8}{*}{ Model 6} & (Intercept) & 269.5000 & 9.1030 & 29.6050 & 0.0000 \\
\hline & $\mathrm{LST}_{\mathrm{td}}$ & 0.1712 & 0.0195 & 8.7690 & 0.0000 \\
\hline & $\mathrm{LST}_{\mathrm{tn}}$ & 0.5073 & 0.0274 & 18.5120 & 0.0000 \\
\hline & $\mathrm{LST}_{\mathrm{ad}}$ & 0.2238 & 0.0182 & 12.3170 & 0.0000 \\
\hline & $\operatorname{LST}_{\mathrm{an}}$ & 0.1649 & 0.0261 & 6.3190 & 0.0000 \\
\hline & Ele & -0.0029 & 0.0001 & -20.6540 & 0.0000 \\
\hline & Long & -2.5100 & 0.0857 & -29.2840 & 0.0000 \\
\hline & $\mathrm{Jd}$ & -0.0019 & 0.0004 & -5.1030 & 0.0000 \\
\hline \multirow{9}{*}{ Model 7} & (Intercept) & 270.1000 & 9.0700 & 29.7730 & 0.0000 \\
\hline & $\mathrm{LST}_{\mathrm{td}}$ & 0.1868 & 0.0201 & 9.3050 & 0.0000 \\
\hline & $\mathrm{LST}_{\mathrm{tn}}$ & 0.4746 & 0.0292 & 16.2390 & 0.0000 \\
\hline & $\mathrm{LST}_{\mathrm{ad}}$ & 0.2178 & 0.0182 & 11.9700 & 0.0000 \\
\hline & $\mathrm{LST}_{\mathrm{an}}$ & 0.1886 & 0.0271 & 6.9660 & 0.0000 \\
\hline & Ele & -0.0029 & 0.0001 & -20.8160 & 0.0000 \\
\hline & Long & -2.5130 & 0.0854 & -29.4290 & 0.0000 \\
\hline & $\mathrm{Jd}$ & -0.0020 & 0.0004 & -5.3020 & 0.0000 \\
\hline & $\mathrm{VZA}_{\mathrm{ad}}$ & -0.0037 & 0.0012 & -3.1350 & 0.0018 \\
\hline \multirow{13}{*}{ Model 8} & (Intercept) & 285.4000 & 9.9020 & 28.8230 & 0.0000 \\
\hline & $\mathrm{LST}_{\mathrm{td}}$ & 0.1812 & 0.0218 & 8.3240 & 0.0000 \\
\hline & $\mathrm{LST}_{\mathrm{tn}}$ & 0.4523 & 0.0314 & 14.3870 & 0.0000 \\
\hline & $\mathrm{LST}_{\mathrm{ad}}$ & 0.2445 & 0.0212 & 11.5410 & 0.0000 \\
\hline & $\mathrm{LST}_{\mathrm{an}}$ & 0.2013 & 0.0294 & 6.8500 & 0.0000 \\
\hline & NDVI & 1.6500 & 0.3829 & 4.3090 & 0.0000 \\
\hline & Ele & -0.0033 & 0.0002 & -19.8170 & 0.0000 \\
\hline & Long & -2.5080 & 0.0847 & -29.6040 & 0.0000 \\
\hline & Lat & -0.7172 & 0.1754 & -4.0890 & 0.0000 \\
\hline & Dlth & -0.1648 & 0.0950 & -1.7350 & 0.0829 \\
\hline & $\mathrm{Jd}$ & -0.0024 & 0.0004 & -6.0140 & 0.0000 \\
\hline & $\mathrm{VZA}_{\mathrm{td}}$ & 0.0021 & 0.0013 & 1.6460 & 0.1001 \\
\hline & $\mathrm{VZA}_{\mathrm{ad}}$ & -0.0038 & 0.0012 & -3.2710 & 0.0011 \\
\hline \multirow{8}{*}{ Model 9} & (Intercept) & 4.6214 & 1.2432 & 3.7170 & 0.0002 \\
\hline & $\mathrm{LST}_{\mathrm{td}}$ & 0.1701 & 0.0259 & 6.5730 & 0.0000 \\
\hline & $\mathrm{LST}_{\mathrm{tn}}$ & 0.5597 & 0.0367 & 15.2720 & 0.0000 \\
\hline & $\mathrm{LST}_{\mathrm{ad}}$ & 0.4074 & 0.0225 & 18.0830 & 0.0000 \\
\hline & $\mathrm{LST}_{\mathrm{an}}$ & -0.0463 & 0.0337 & -1.3720 & 0.1704 \\
\hline & Ele & -0.0013 & 0.0002 & -7.2070 & 0.0000 \\
\hline & Dlth & -0.1617 & 0.1235 & -1.3090 & 0.1907 \\
\hline & $\mathrm{Jd}$ & -0.0013 & 0.0005 & -2.5570 & 0.0107 \\
\hline
\end{tabular}




\section{Appendix B}

Table B1. Parameters of Models for $\mathrm{T}_{\mathrm{a}-\text {-min }}$ Estimation.

\begin{tabular}{|c|c|c|c|c|c|}
\hline & & Estimate & Std. Error & $t$-Value & $p$-Value \\
\hline \multirow{2}{*}{ Model 10} & (Intercept) & -1.5176 & 0.2085 & -7.2800 & 0.0000 \\
\hline & $\mathrm{LST}_{\mathrm{an}}$ & 1.0157 & 0.0121 & 83.9300 & 0.0000 \\
\hline \multirow{3}{*}{ Model 11} & (Intercept) & -2.4950 & 0.2178 & -11.4600 & 0.0000 \\
\hline & $\mathrm{LST}_{\mathrm{tn}}$ & 0.4055 & 0.0371 & 10.9200 & 0.0000 \\
\hline & $\mathrm{LST}_{\text {an }}$ & 0.6492 & 0.0355 & 18.2900 & 0.0000 \\
\hline \multirow{4}{*}{ Model 12} & (Intercept) & -1.4608 & 0.3340 & -4.3730 & 0.0000 \\
\hline & $\mathrm{LST}_{\mathrm{tn}}$ & 0.4496 & 0.0385 & 11.6920 & 0.0000 \\
\hline & $\mathrm{LST}_{\mathrm{ad}}$ & -0.0620 & 0.0153 & -4.0640 & 0.0001 \\
\hline & $\mathrm{LST}_{\text {an }}$ & 0.6541 & 0.0353 & 18.5420 & 0.0000 \\
\hline \multirow{5}{*}{ Model 13} & (Intercept) & -1.6875 & 0.3420 & -4.9350 & 0.0000 \\
\hline & $\mathrm{LST}_{\mathrm{td}}$ & 0.0800 & 0.0275 & 2.9080 & 0.0037 \\
\hline & $\mathrm{LST}_{\mathrm{tn}}$ & 0.4417 & 0.0384 & 11.4950 & 0.0000 \\
\hline & $\mathrm{LST}_{\mathrm{ad}}$ & -0.1139 & 0.0235 & -4.8570 & 0.0000 \\
\hline & $\mathrm{LST}_{\mathrm{an}}$ & 0.6425 & 0.0354 & 18.1590 & 0.0000 \\
\hline \multirow{7}{*}{ Model 14} & (Intercept) & -10.9000 & 1.3100 & -8.3200 & 0.0000 \\
\hline & $\mathrm{LST}_{\mathrm{td}}$ & 0.0544 & 0.0271 & 2.0060 & 0.0450 \\
\hline & $\mathrm{LST}_{\mathrm{tn}}$ & 0.4210 & 0.0382 & 11.0130 & 0.0000 \\
\hline & $\mathrm{LST}_{\mathrm{ad}}$ & -0.0931 & 0.0239 & -3.9020 & 0.0001 \\
\hline & $\mathrm{LST}_{\mathrm{an}}$ & 0.5800 & 0.0358 & 16.2000 & 0.0000 \\
\hline & Dlth & 0.8850 & 0.1280 & 6.9320 & 0.0000 \\
\hline & $\mathrm{Jd}$ & 0.0020 & 0.0005 & 3.6870 & 0.0002 \\
\hline \multirow{8}{*}{ Model 15} & (Intercept) & 6.4498 & 5.2374 & 1.2310 & 0.2184 \\
\hline & $\mathrm{LST}_{\mathrm{td}}$ & 0.0479 & 0.0271 & 1.7700 & 0.0769 \\
\hline & $\mathrm{LST}_{\mathrm{tn}}$ & 0.4187 & 0.0380 & 11.0110 & 0.0000 \\
\hline & $\mathrm{LST}_{\mathrm{ad}}$ & -0.0998 & 0.0238 & -4.1890 & 0.0000 \\
\hline & $\mathrm{LST}_{\mathrm{an}}$ & 0.5885 & 0.0357 & 16.4770 & 0.0000 \\
\hline & Dlth & 0.9112 & 0.1273 & 7.1560 & 0.0000 \\
\hline & Jd & 0.0020 & 0.0005 & 3.7160 & 0.0002 \\
\hline & Lat & -0.8214 & 0.2397 & -3.4280 & 0.0006 \\
\hline \multirow{9}{*}{ Model 16} & (Intercept) & 7.0965 & 5.2666 & 1.3470 & 0.1781 \\
\hline & $\mathrm{LST}_{\mathrm{td}}$ & 0.0529 & 0.0274 & 1.9320 & 0.0537 \\
\hline & $\mathrm{LST}_{\mathrm{tn}}$ & 0.4097 & 0.0388 & 10.5540 & 0.0000 \\
\hline & $\mathrm{LST}_{\mathrm{ad}}$ & -0.1027 & 0.0239 & -4.2870 & 0.0000 \\
\hline & $\mathrm{LST}_{\mathrm{an}}$ & 0.5864 & 0.0358 & 16.3970 & 0.0000 \\
\hline & Dlth & 0.9479 & 0.1312 & 7.2230 & 0.0000 \\
\hline & Jd & 0.0019 & 0.0005 & 3.5110 & 0.0005 \\
\hline & Lat & -0.8599 & 0.2419 & -3.5540 & 0.0004 \\
\hline & Ele & -0.0002 & 0.0002 & -1.1540 & 0.2487 \\
\hline \multirow{11}{*}{ Model 17} & (Intercept) & 10.9860 & 5.3900 & 2.0380 & 0.0418 \\
\hline & $\mathrm{LST}_{\mathrm{td}}$ & 0.0740 & 0.0284 & 2.6070 & 0.0093 \\
\hline & $\mathrm{LST}_{\mathrm{tn}}$ & 0.3827 & 0.0412 & 9.2900 & 0.0000 \\
\hline & $\mathrm{LST}_{\mathrm{ad}}$ & -0.0913 & 0.0245 & -3.7250 & 0.0002 \\
\hline & $\mathrm{LST}_{\mathrm{an}}$ & 0.5887 & 0.0376 & 15.6640 & 0.0000 \\
\hline & NDVI & 1.6296 & 0.5405 & 3.0150 & 0.0026 \\
\hline & Ele & -0.0006 & 0.0002 & -2.5960 & 0.0096 \\
\hline & Lat & -1.0290 & 0.2479 & -4.1510 & 0.0000 \\
\hline & Dlth & 0.8447 & 0.1343 & 6.2910 & 0.0000 \\
\hline & Jd & 0.0015 & 0.0005 & 2.6990 & 0.0071 \\
\hline & $\mathrm{VZA}_{\mathrm{ad}}$ & -0.0027 & 0.0016 & -1.6590 & 0.0973 \\
\hline \multirow{8}{*}{ Model 18} & (Intercept) & -11.0000 & 1.3200 & -8.3410 & 0.0000 \\
\hline & $\mathrm{LST}_{\mathrm{td}}$ & 0.0575 & 0.0275 & 2.0890 & 0.0369 \\
\hline & $\mathrm{LST}_{\mathrm{tn}}$ & 0.4160 & 0.0390 & 10.6610 & 0.0000 \\
\hline & $\mathrm{LST}_{\mathrm{ad}}$ & -0.0946 & 0.0240 & -3.9460 & 0.0001 \\
\hline & $\mathrm{LST}_{\mathrm{an}}$ & 0.5790 & 0.0359 & 16.1250 & 0.0000 \\
\hline & Ele & -0.0001 & 0.0002 & -0.6680 & 0.5043 \\
\hline & Dlth & 0.9060 & 0.1310 & 6.8960 & 0.0000 \\
\hline & Jd & 0.0019 & 0.0005 & 3.5520 & 0.0004 \\
\hline
\end{tabular}




\section{References}

1. De Bruin, H.A.R.; Trigo, I.F.; Jitan, M.A.; TemesgenEnku, N.; van der Tol, C.; Gieske, A.S.M. Reference crop evapotranspiration derived from geo-stationary satellite imagery: A case study for the Fogera flood plain, NW-Ethiopia and the Jordan Valley, Jordan. Hydrol. Earth Syst. Sci. 2010, 14, 2219-2228. [CrossRef]

2. Balaghi, R.; Tychon, B.; Eerens, H.; Jlibene, M. Empirical regression models using NDVI, rainfall and temperature data for early prediction of wheat grain yields in Morocco. Int. J. Appl. Earth Obs. 2008, 10, 438-452. [CrossRef]

3. De Wit, A.J.W.; van Diepen, C.A. Crop growth modelling and crop yield forecasting using satellite-derived meteorological inputs. Int. J. Appl. Earth Obs. 2008, 10, 414-425. [CrossRef]

4. Lehman, J.T. Application of satellite AVHRR to water balance mixing dynamics and the chemistry of Lake Edward, East Africa. In The East African Great Lakes: Limnology, Palaeolimnology and Biodiversity; Odada, E.O., Olago, D.O., Eds.; Kluwer Academic Publishers: Dordrecht, The Netherlands, 2002; pp. 235-260.

5. Vallet-Coulomb, C.; Legesse, D.; Gasse, F.; Travi, Y.; Chernet, T. Lake evaporation estimates in tropical Africa (Lake Ziway, Ethiopia). J. Hydrol. 2001, 245, 1-18. [CrossRef]

6. Intergovernmental Panel on Climate Change (IPCC). Climate Change 2001: The Scientific Basis; Contribution of Working Group I to the Third Assessment Report of the Intergovernmental Panel on Climate Change; Cambridge University Press: Cambridge, UK, 2001; p. 881.

7. Intergovernmental Panel on Climate Change (IPCC). Climate Change 2007: The Physical Science Basis; Contribution of Working Group I to the Fourth Assessment Report of the Intergovernmental Panel on Cli-mate Change; Solomon, S., Qin, D., Manning, M., Chen, Z., Marquis, M., Averyt, K.B., Tignor, M., Miller, H.L., Eds.; Cambridge University Press: Cambridge, UK, 2007.

8. Fu, G.; Shen, Z.X.; Zhang, X.Z.; Shi, P.L.; Zhang, Y.J.; Wu, J.S. Estimating air temperature of an alpine meadow on the Northern Tibetan Plateau using MODIS land surface temperature. Acta Ecol. Sin. 2011, 21, 8-13. [CrossRef]

9. Stisen, S.; Sandholt, I.; Norgaard, A.; Fensholt, R.; Eklundh, L. Estimation of diurnal air temperature using MSG SEVIRI data in West Africa. Remote Sens. Environ. 2007, 110, 262-274. [CrossRef]

10. Nieto, H.; Sandholt, I.; Aguado, I.; Chuvieco, E.; Stisen, S. Air temperature estimation with MSG-SEVIRI data: Calibration and validation of the TVX algorithm for the Iberian Peninsula. Remote Sens. Environ. 2011, 115, 107-116. [CrossRef]

11. Lin, S.; Moore, N.J.; Messina, J.P.; de Visser, M.H.; Wu, J. Evaluation of estimating daily maximum and minimum air temperature with MODIS data in east Africa. Int. J. Appl. Earth Obs. Geoinf. 2012, 18, 128-140. [CrossRef]

12. Basist, A.N.; Peterson, N.C.; Peterson, T.C.; Williams, C.N. Using the special sensor mi-crowave/imager to monitor land surface temperature, wetness, and snow cover. J. Appl. Meteorol. 1998, 37, 888-911. [CrossRef]

13. Peterson, T.C.; Basist, A.N.; Williams, C.; Grody, N. A blended satellite/in situ near-global surface temperature data set. Bull. Am. Meteorol. Soc. 2000, 81, 2157-2164. [CrossRef]

14. Florio, E.N.; Lele, S.R.; Chi Chang, Y.; Sterner, R.; Glass, G.E. Integrating AVHRR satellite data and NOAA ground observations to predict surface air temperature: A statistical approach. Int. J. Remote Sens. 2004, 25, 2979-2994. [CrossRef]

15. Vancutsem, C.; Ceccato, P.; Dinku, T.; Connor, S.J. Evaluation of MODIS land surface temperature data to estimate air temperature in different ecosystems over Africa. Remote Sens. Environ. 2010, 114, 449-465. [CrossRef]

16. Vogt, J.V.; Viau, A.A.; Paquet, F. Mapping regional air temperature fields using satellite-derived surface skin temperatures. Int. J. Climatol. 1997, 17, 1559-1579. [CrossRef]

17. Lai, Y.J.; Li, C.F.; Lin, P.H.; Wey, T.H.; Chang, C.S. Comparison of MODIS land surface temperature and ground-based observed air temperature in complex topography. Int. J. Remote Sens. 2012, 33, 7685-7702. [CrossRef]

18. Sun, H.; Chen, Y.; Gong, A.; Zhao, X.; Zhan, W.; Wang, M. Estimating mean air temperature using MODIS day and night land surface temperatures. Theor. Appl. Climatol. 2014, 118, 81-92. [CrossRef]

19. Dinh, V.V. Country Report the hydro meteorological service of Vietnam and its modernization plan. In Proceedings of the 5th Global Precipitation Measurement (GPM) International Planning Workshop, Tokyo, Japan, 7-9 November 2005. 
20. Coll, C.; Caselles, V.; Sobrino, J.A.; Valor, E. On the atmospheric dependence of the split-window equation for land surface temperature. Int. J. Remote Sens. Environ. 1994, 27, 105-122. [CrossRef]

21. Wan, Z.; Dozier, J. A generalized split-window algorithm for retrieving land-surface temperature from space. IEEE Trans. Geosci. Remote Sens. 1996, 34, 892-905.

22. Cresswell, M.P.; Morse, A.P.; Thomson, M.C.; Connor, S.J. Estimating surface air temperatures, from Meteosat land surface temperatures, using an empirical solar zenith angle model. Int. J. Remote Sens. 1999, 20, 1125-1132. [CrossRef]

23. Williamson, S.; Hik, D.; Gamon, J.; Kavanaugh, J.; Flowers, G. Estimating temperature fields from MODIS land surface temperature and air temperature observations in a sub-arctic alpine environment. Remote Sens. 2014, 6, 946-963. [CrossRef]

24. Prince, S.D.; Goetz, S.J.; Dubayah, R.O.; Czajkowski, K.P.; Thawley, M. Inference of surface and air temperature, atmospheric precipitable water and vapor pressure deficit using advanced very high-resolution radiometer satellite observations: Comparison with field observations. J. Hydrol. 1998, 213, 230-249. [CrossRef]

25. Mostovoy, G.V.; King, R.L.; Reddy, K.R.; Kakani, V.G.; Filippova, M.G. Statistical estimation of daily maximum and minimum air temperatures from MODIS LST data over the state of Mississippi. GISci. Remote Sens. 2006, 43, 78-110. [CrossRef]

26. Jin, M.; Dickinson, R.E. Land surface skin temperature climatology: Benefitting from the strengths of satellite observations. Environ. Res. Lett. 2010, 5, 044004. [CrossRef]

27. Lin, X.; Zhang, W.; Huang, Y.; Sun, W.; Han, P.; Yu, L.; Sun, F. Empirical estimation of near-surface air temperature in China from MODIS LST data by considering physiographic features. Remote Sens. 2016, 8, 629. [CrossRef]

28. Gallo, K.; Hale, R.; Tarpley, D.; YU, Y. Evaluation of the relationship between air and land surface temperature under clear- and cloudy-sky conditions. J. Appl. Meteorol. Climatol. 2011, 50, 767-775. [CrossRef]

29. Benali, A.; Carvalho, A.C.; Nunes, J.P.; Carvalhais, N.; Santos, A. Estimating air surface temperature in Portugal using MODIS LST data. Remote Sens. Environ. 2012, 124, 108-121. [CrossRef]

30. Crosson, W.L.; Al-Hamdan, M.Z.; Hemmings, S.N.; Wade, G.M. A daily merged MODIS Aqua-Terra land surface temperature data set for the conterminous United States. Remote Sens. Environ. 2012, 119, 315-324. [CrossRef]

31. Zeng, L.; Wardlow, B.D.; Tadesse, T.; Shan, J.; Hayes, M.J.; Li, D.; Xiang, D. Estimation of daily air temperature based on MODIS land surface temperature products over the corn belt in the US. Remote Sens. 2015, 7, 951-970. [CrossRef]

32. Xu, Y.; Qin, Z.; Shen, Y. Study on the estimation of near-surface air temperature from MODIS data by statistical methods. Int. J. Remote Sens. 2012, 33, 7629-7643. [CrossRef]

33. Huang, R.; Zhang, C.; Huang, J.; Zhu, D.; Wang, L.; Liu, J. Mapping of daily mean air temperature in agricultural regions using daytime and nighttime land surface temperatures derived from Terra and Aqua MODIS data. Remote Sens. 2015, 7, 8728-8756. [CrossRef]

34. Zakšek, K.; Schroedter-Homscheidt, M. Parameterization of air temperature in high temporal and spatial resolution from a combination of the SEVIRI and MODIS instruments. ISPRS J. Photogramm. Remote Sens. 2009, 64, 414-421. [CrossRef]

35. Prihodko, L.; Goward, S.N. Estimation of air temperature from remotely sensed surface observations. Remote Sens. Environ. 1997, 60, 335-346. [CrossRef]

36. Goetz, S.J. Multi-sensor analysis of NDVI, surface temperature and biophysical variables at amixed grassland site. Int. J. Remote Sens. 1997, 18, 71-94. [CrossRef]

37. Goetz, S.J.; Prince, S.D.; Small, J. Advances in satellite remote sensing of environmental variables for epidemiological applications. Adv. Parasitol. 2000, 47, 289-307. [PubMed]

38. Zhu, W.; Lú, A.; Jia, S. Estimation of daily maximum and minimum air temperature using MODIS land surface temperature products. Remote Sens. Environ. 2013, 130, 62-73. [CrossRef]

39. Sun, H.; Zhao, X.; Chen, Y.; Gong, A.; Yang, J. A new agricultural drought monitoring index combining MODIS NDWI and day-night land surface temperatures: A case study in China. Int. J. Remote Sens. 2013, 34, 8986-9001. [CrossRef]

40. Sandholt, I.; Rasmussen, K.; Andersen, J. A simple interpretation of the surface temperature/vegetation index space for assessment of surface moisture status. Remote Sens. Environ. 2002, 79, 213-224. [CrossRef] 
41. Sun, Y.J.; Wang, J.F.; Zhang, R.H.; Gillies, R.R.; Xue, Y.; Bo, Y.C. Air temperature retrieval from remote sensing data based on thermodynamics. Theor. Appl. Climatol. 2005, 80, 37-48. [CrossRef]

42. Zhang, W.; Huang, Y.; Yu, Y.; Sun, W. Empirical models for estimating daily maximum, minimum and mean air temperatures with MODIS land surface temperatures. Int. J. Remote Sens. 2011, 32, 9415-9440. [CrossRef]

43. Good, E. Daily minimum and maximum surface air temperatures from geostationary satellite data. J. Geophys. Res. Atmos. 2015, 120, 2306-2324. [CrossRef]

44. Zhang, R.; Rong, Y.; Tian, J.; Su, H.; Li, Z.L.; Liu, S. A remote sensing method for estimating surface air temperature and surface vapor pressure on a regional scale. Remote Sens. 2015, 7, 6005-6025. [CrossRef]

45. Janatian, N.; Sadeghi, M.; Sanaeinejad, S.H.; Bakhshian, E.; Farid, A.; Hasheminia, S.M.; Ghazanfari, S. A statistical framework for estimating air temperature using MODIS land surface temperature data. Int. J. Climatol. 2016. [CrossRef]

46. Shen, S.; Leptoukh, G.G. Estimation of surface air temperature over central and eastern Eurasia from MODIS land surface temperature. Environ. Res. Lett. 2011, 6, 045206. [CrossRef]

47. Emamifar, S.; Rahimikhoob, A.; Noroozi, A. Daily mean air temperature estimation from MODIS land surface temperature products based on M5 model tree. Int. J. Climatol. 2013, 33, 3174-3181. [CrossRef]

48. Xu, Y.; Knudby, A.; Ho, H.C. Estimating daily maximum air temperature from MODIS in British Columbia, Canada. Int. J. Remote Sens. 2014, 35, 8108-8121. [CrossRef]

49. NASA Visible Earth. Available online: http://visibleearth.nasa.gov/view.php?id=35791 (accessed on 12 October 2015).

50. The U.S. Geological Survey. MODIS LST Data. Available online: http://earthexplorer.usgs.gov (accessed on 1 August 2015).

51. Wan, Z.; Zhang, Y.; Zhang, Q.; Li, Z.L. Validation of the land-surface temperature products retrieved from Terra Moderate Resolution Imaging Spectroradiometer data. Remote Sens. Environ. 2002, 83, 163-180. [CrossRef]

52. The Report of MOD11A1 and MYD11A1 Validation Accuracy. Available online: http:/ /landval.gsfc.nasa. gov/ProductStatus.php?ProductID=MOD11 (accessed on 2 November 2015).

53. Shi, L.; Liu, P.; Kloog, I.; Lee, M.; Kosheleva, A.; Schwartz, J. Estimating daily air temperature across the Southeastern United States using high-resolution satellite data: A statistical modeling study. Environ. Res. 2016, 146, 51-58. [CrossRef] [PubMed]

54. Miura, T.; Yoshioka, H.; Fujiwara, K.; Yamamoto, H. Inter-comparison of ASTER and MODIS surface reflectance and vegetation index products for synergistic applications to natural resource monitoring. Sensors 2008, 8, 2480-2499. [CrossRef] [PubMed]

55. The United States Naval Observatory (USNO). Day Length in Hours Data. Available online: http://aa.usno. navy.mil/data/docs/Dur_OneYear.php\#formb (accessed on 1 December 2015).

56. Land Quality Assessment Site of NASA. Julian Day. Available online: http://landweb.nascom.nasa.gov/ browse/calendar.html (accessed on 2 November 2015).

57. Jang, J.D.; Viau, A.A.; Anctil, F. Neural network estimation of air temperatures from AVHRR data. Int. J. Remote Sens. 2004, 25, 4541-4554. [CrossRef]

58. Wan, Z. MODIS Land Surface Temperature Products Users' Guide. Available online: http://www.icess.ucsb. edu/modis/LstUsrGuide/MODIS_LST_products_Users_guide_C5.pdf (accessed on 19 November 2015).

59. Kilibarda, M.; Hengl, T.; Heuvelink, G.; Gräler, B.; Pebesma, E.; Perčec Tadić, M.; Bajat, B. Spatio-temporal interpolation of daily temperatures for global land areas at $1 \mathrm{~km}$ resolution. J. Geophys. Res. Atmos. 2014, 119, 2294-2313. [CrossRef]

60. Shamir, E.; Georgakakos, K.P. MODIS land surface temperature as an index of surface air temperature for operational snowpack estimation. Remote Sens. Environ. 2014, 152, 83-98. [CrossRef]

(C) 2016 by the authors; licensee MDPI, Basel, Switzerland. This article is an open access article distributed under the terms and conditions of the Creative Commons Attribution (CC-BY) license (http://creativecommons.org/licenses/by/4.0/). 